Article

\title{
Do Nonparametric Measures of Extreme Equity Risk Change the Parametric Ordinal Ranking? Evidence from Asia
}

\author{
Robert J. Powell ${ }^{1, *(D)}$, Duc H. Vo ${ }^{2}$ and Thach N. Pham ${ }^{2} \mathbb{D}$ \\ 1 School of Business and Law, Edith Cowan University, 270 Joondalup Drive, Joondalup 6027, Australia \\ 2 Business and Economics Research Centre, Ho Chi Minh City Open University, 97 Vo Van Tan Street, District \\ 3, Ho Chi Minh City 700,000, Vietnam; duc.vhong@ou.edu.vn (D.H.V.); thach.pn@ou.edu.vn (T.N.P.) \\ * Correspondence: r.powell@ecu.edu.au
}

Received: 10 September 2018; Accepted: 11 October 2018; Published: 14 October 2018

check for updates

\begin{abstract}
There has been much discussion in the literature about how central measures of equity risk such as standard deviation fail to account for extreme tail risk of equities. Similarly, parametric measures of value at risk (VaR) may also fail to account for extreme risk as they assume a normal distribution which is often not the case in practice. Nonparametric measures of extreme risk such as nonparametric VaR and conditional value at risk (CVaR) have often been found to overcome this problem by measuring actual tail risk without applying any predetermined assumptions. However, this article argues that it is not just the actual risk of equites that is important to investor choices, but also the relative (ordinal) risk of equities compared to each other. Using an applied setting of industry portfolios in a variety of Asian countries (benchmarked to the United States), over crisis and non-crisis periods, this article finds that nonparametric measures of $\mathrm{VaR}$ and $\mathrm{CVaR}$ may provide only limited new information to investors about relative risk in the portfolios examined as there is a high degree of similarity found in relative industry risk when using nonparametric metrics as compared to central or parametric measures such as standard deviation and parametric VaR.
\end{abstract}

Keywords: VaR; conditional value at risk; parametric; nonparametric; Asian industries

\section{Introduction}

Background and Rationale

This study focuses on differences between parametric and nonparametric measures of relative industry risk among equities in Asia. Volatility in equity markets can provide an indicator of relative risk among industries which can be important, not only to investors who seek to optimize the risk and return of their portfolios, but also to lenders who seek to reduce risk in their lending portfolios and to policy makers who seek to identify industry risk that may have adverse impacts on the economy.

The literature abounds with studies which show nonparametric extreme measures of risk, such as conditional value at risk ( $\mathrm{CVaR})$, to better account for tail risk than central measures such as standard deviation or parametric measures which assume a normal distribution such as parametric value at risk (VaR). This is especially during crisis periods when there may be outliers in the tail of a distribution. These studies predominantly focus on the US or other developed regions, which tended to suffer extreme risk during the Global Financial Crisis (GFC). To provide somewhat of a contrast, this study focuses on the Asian region which had a far more moderate experience during that crisis. Most studies also predominantly focus on actual measurements of extreme risk, rather than on ordinal measures which rank equities and portfolios. While actual measures of extreme risk such as CVaR can be very useful in understanding the extreme risk in the tail of a distribution, ordinal measures are useful in 
comparing how the risk of equities or equities portfolios change relative to each other. Put another way, if the overall market risk of equities increases in a crisis period, does the tail risk of different industry portfolios all increase relatively equally (meaning that central measures such as standard deviation are equally as good as tail measures such as CVaR in determining relative risk), or does CVaR provide additional information about relative risk not captured by the standard deviation measure?

VaR measures of industry risk in this study include parametric VaR, which assumes a normal distribution, historical VaR which is based on the actual prior returns and makes no assumptions about the distribution, and Cornish-Fisher VaR (also known as modified VaR, which we will call it henceforth) which modifies parametric VaR by applying a Cornish and Fisher (1938) modification to a normal distribution, taking into account kurtosis and skewness. The study also includes CVaR which measures volatility in the tail of the distribution and, as such, can capture information which is not identified by the VaR metrics that only measure risk up to a specified threshold. The study does not separately include standard deviation as a metric, given that parametric VaR assumes a normal distribution which is effectively just a multiple applied to standard deviation and therefore these two measures will always provide an identical ordinal outcome when used to rank portfolios. Therefore, we only use one of these two measures - parametric VaR. On the other hand, historical VaR, modified VaR, and CVaR are non-Gaussian measures, which can result in a different ordinal ranking for a portfolio as compared to rankings based on standard deviation or parametric VaR. In addition to a straightforward ordinal ranking approach, to account for covariance between industry portfolios, this study also applies a Markowitz (1952) type of model to measure relative ordinal contribution of industries to a portfolio of stocks, using the different VaR metrics in this study and CVaR as portfolio risk optimizers in place of the traditional standard deviation or variance approach. More detail about the metrics and ranking approach used is provided in the materials and methods discussion in Section 2.

The study includes China, Japan, and the ASEAN (Association of Southeast Asian Nations) region (made up of the largest six countries in the ASEAN region including Indonesia, Malaysia, Philippines, Singapore, Thailand, and Vietnam). This provides a mix of smaller and larger economies (with China and Japan among the world top four economies by GDP), and the ASEAN countries comprising of mainly developing countries as classified by the IMF (International Monetary Fund 2017), except for the developed country of Singapore. The US is included as a benchmark comparison. Ten industries are compared in the study (Oil and Gas, Basic Materials, Industrials, Consumer Goods, Health Care, Consumer Services, Telecommunications, Utilities, Financials and Technology) further details of which are provided in the materials and method discussion in Section 2.

There are two research questions explored by the study. Firstly, whether there is significant similarity between each of the each of the metrics (parametric VaR, historical VaR, modified VaR and $\mathrm{CVaR}$ ) in how they rank industry risk. Secondly, whether these similarities or differences between the metrics change in a crisis period as compared to a non-crisis period. We examine risk over a 10-year period from 2007 to 2016, which includes the GFC and separate the sample into crisis (2007-2009) and non-crisis (the remaining) years. To ascertain whether the rankings are sensitive to different levels extreme of extreme risk, we use both 95\% and 99\% confidence levels in our VaR and CVaR metrics.

As well as there being relatively few studies on tail risk in Asia, there is also a very limited number of prior studies on industry equities risk in Asia, most of which have focused on individual (or a small range of) countries or which use other combinations of metrics to ours, or which examine earlier years, or which do not focus on ordinal risk. As far as we can ascertain this is the first study which provides such a comprehensive exploration of differences between metrics in ordinal risk, using those countries and metrics examined in this study.

Regarding tail risk, using VaR and CVaR, Hakamada et al. (2007) found that distributions of Asia-Pacific hedge fund returns are not necessarily Gaussian and that CVaR could better account for fat tails than standard deviation. Lim (2012) examined a range of global markets including Asia and found that from 2008 (GFC) onwards, portfolio return distributions have tails that simultaneously grow longer and thinner in the direction of the loss region, and that risk would be underestimated 
by using normal distribution models. Various other global studies have also found measures such as standard deviation and other parametric measures to inadequately account for tail risk, for example Uryasev and Rockafellar (2000), Furió and Climent (2013), and Del Brio et al. (2014). On the other hand, Allen et al. (2012) found equities for sectors in Indonesia to be fairly stable over the GFC, and that parametric (normally distributed) measures of $\mathrm{VaR}$ and $\mathrm{CVaR}$ yielded similar results to nonparametric ones which do not apply a normal distribution assumption.

Most studies on equities risk in Asia surrounding crisis periods have focused on integration between Asian and non-Asian markets and whether this integration changes between crisis and non-crisis periods (for example, Click and Plummer 2005; Chiang et al. 2007; Chuang et al. 2007; Yang et al. 2010; Brown et al. 2014; Batten et al. 2015; Rejeb and Arfaoui 2016), rather than focusing on differences in ordinal rankings between metrics such as we do in this study. Regarding industry risk, studies have generally focused on which industries over the periods have been more affected (for example, Baur 2012; Kenourgios and Dimitriou 2015) rather than on differences between metrics as undertaken in this study.

Generally, prior studies have found that integration between countries in Asia increases during and after a crisis, that some industries are affected more than others during a crisis meaning that relative risk between industries may change, and that while normal distribution models can often inadequately measure risk, this is not necessarily always the case.

This study, on the other hand, finds that there is significant similarity in ordinal industry rankings in the selected countries between all the metrics used. This means that, from an ordinal perspective, the nonparametric measures of historical VaR and CVaR and the non-Gaussian modified VaR provide only limited new information to investors (or other interested parties such as lenders and regulators), about relative industry risk than what is captured by parametric VaR (and therefore also by standard deviation).

The remainder of the study is structured as follows. Section 2 explains our data and methodology, including details and justification for the metrics used and the ordinal ranking approach. Section 3 presents and discusses the results. Section 4 concludes.

\section{Materials and Methods}

This section will describe our data sources, then explain our VaR and CVaR methodology, followed by an explanation of the ordinal methodology that we use to rank industry risk.

\subsection{Data}

We use the DataStream Industry Indices for each country in our study. These indices are based on the ten industries of the well-known Industry Classification Benchmark (ICB) owned by FTSE (Financial Times Stock Exchange) and used by markets across the globe. The industries are Oil and Gas, Basic Materials (Chemicals, Mining and Resources), Industrials (Construction, Industrial Goods and Services), Consumer Goods (Automobiles and Parts, Food and Beverage, Personal and Household Goods), Health Care (Healthcare Equipment and Services, Pharmaceuticals), Consumer Services (Retailers, Media, Travel and Leisure), Telecommunications, Utilities (Electricity, Gas, Water, Multi-utilities), Financials (Banks, Insurance, Real Estate, Financial Services) and Technology (Software, Hardware).

The study includes 10 years of data from 2007 to 2016. Importantly, this includes the GFC period and the years thereafter. In addition to analyzing the total ten-year period, we also split the data into crisis (2007-2009) and non-crisis periods (2010-2016). Data summaries behind the analyses in Section 3 can be found in Appendix A. In Appendix A, Table A1 (95\% confidence level) and Appendix A, Table A2 (99\% confidence level), we provide detailed figures on parametric VaR, historical VaR, modified VaR and CVaR, for each industry in each country for the total period, crisis period and non-crisis period. In Appendix A, Tables $\mathrm{A} 3$ and A4, we provide the rankings for each industry based on the figures in Tables A1 and A2, respectively. 


\subsection{Value at Risk and Conditional Value at Risk}

$\mathrm{VaR}$ is a metric which measures potential losses at a specified level of confidence for a selected period. For example, a daily VaR of 0.02 over 1 year at $95 \%$ confidence level for a share portfolio means that in $95 \%$ of days in that year, the losses should not exceed $2 \%$ of the portfolio's value. VaR can be measured using methods such as a parametric or historical (nonparametric) basis. Parametric VaR assumes a normal distribution and is derived from the standard deviation $(\sigma)$. A key weakness of this approach is that returns may not be normally distributed. Historical (nonparametric) VaR, on the other hand, is based on actual historical values.

If parametric and nonparametric measures are dis-similar, then nonparametric $\mathrm{VaR}$ is capturing information about the relative (ordinal risk) not displayed by the normally distributed parametric approach. Given the differences that can exist between these two measures, we use both parametric and nonparametric measures of $\mathrm{VaR}$ in this study, incorporating a total of three VaR types. This first is a parametric (Gaussian) measure (parametric VaR) which is based on a normal distribution assumption. The second is a nonparametric (non-Gaussian) measure of VaR, also known as historical VaR which makes no distribution assumptions and is based on actual historical returns. The third is modified VaR, which is also known as Cornish-Fisher VaR, and is designed at changing parametric VaR into a non-Gaussian VaR by incorporating historical kurtosis and skewness into the VaR metric.

VaR has been criticized on various grounds, most usually because it disregards returns beyond VaR (Yamai and Yoshiba 2005; Choudhry 2013; Pinelis 2014). For example, 95\% VaR ignores the worst $5 \%$ of returns and $99 \%$ VaR ignores the worst $1 \%$ of returns. This information is captured by CVaR which is based on the returns exceeding VaR and thus makes it suitable for attaining information on tail risk (Uryasev and Rockafellar 2000; Yu et al. 2009; Äijö and Orlov 2015; Allen et al. 2016; $\mathrm{Li}$ and $\mathrm{Xu}$ 2013). CVaR is the average of those returns exceeding VaR. Given the additional information that can be provided by CVaR, we use this measure in our study, which is compared to each of the VaR measures in this study.

$\mathrm{VaR}$ and $\mathrm{CVaR}$ can be expressed as follows:

$$
\begin{gathered}
\varsigma_{(x)}=\operatorname{VaR}_{\alpha(x)}=q_{\alpha(x)} \\
\phi_{(x)}=C V a R_{\alpha(x)}=Q_{\alpha(x)}
\end{gathered}
$$

where $\zeta_{(x)}$ is the $\operatorname{VaR}$ for portfolio $x$ at confidence level $\alpha$ (usually $95 \%$ or $99 \%$ ), $q_{\alpha}$ is the VaR threshold and $\phi_{\alpha(x)}$ is the average returns beyond the VaR threshold (CVaR). In this study, we use $\alpha$ at both $95 \%$ and $99 \%$ levels, given that ordinal rankings may be sensitive to extreme values and thus to the confidence level used. For parametric $\mathrm{VaR}, q_{\alpha(x)}$ is derived from the standard deviation $\sigma$ multiplied by $Z$ (obtained from normal distribution tables), where $Z$ at a $95 \%$ confidence level $=1.645$ and at a $99 \%$ confidence level $=2.326$. For historical $\mathrm{VaR} q_{\alpha(x)}$ is the actual historical 95 percentile lowest return. For modified VaR, $q_{\alpha(x)}$ is obtained using the mean of returns plus standard deviation $\sigma$ multiplied by a modified $Z$ which considers skewness $(S)$ and kurtosis $(K)$ as follows:

$$
Z_{\text {modified }}=\left(Z+\frac{1}{6}\left(Z^{2}-1\right) S+\frac{1}{24}\left(Z^{3}-3 Z\right) K-\frac{1}{36}\left(2 Z^{3}-5 Z\right) S^{2}\right)
$$

In this study, CVaR is measured on actual returns, rather than on any assumed distribution. Given that CVaR is the average of returns beyond $\mathrm{VaR}, 95 \% \mathrm{CVaR}$ is the average of the lowest $5 \%$ of returns (the average of those returns beyond the $95 \% \mathrm{VaR}$ ), and $99 \% \mathrm{CVaR}$ is the average of the lowest $1 \%$ of returns (the average of those returns beyond the $99 \% \mathrm{VaR}$ ).

To measure VaR and CVaR, we calculate daily returns for every day in our sample and then calculate the annual VaR or CVaR measure for each of the ten years in the sample, using Equations (1)-(3) at both $95 \%$ and $99 \%$ levels . The VaR for each of the three periods (total period, crisis period and non-crisis period) is calculated as the average annual VaR for that period. 
In summary, there are two Gaussian parametric measures used in this study (95\% parametric VaR and 99\% parametric VaR) which will be compared to six non-Gaussian measures, including 95\% historical VaR and 99\% historical VaR, 95\% modified VaR and 99\% modified VaR, and 95\% CVaR and $99 \% \mathrm{CVaR}$ (the latter two metrics measuring the worst $5 \%$ and $1 \%$ of returns respectively).

\subsection{Ranking Methodology}

Ordinal rankings are not meant to tell you about exact characteristics of the underlying items being evaluated. Rather, they tell you about what is better relative to other items. So, during a crisis, the actual risk of equities may change, but if the risk of all the equities increase, the ranking may not change. Ordinal rankings provide information about relative quality and have the advantage of being able to see which item is the best or worst quickly and easily.

According to Dedania et al. (2015), ranking and evaluating stocks is a very important issue to identify superior firms or portfolios. The authors see the ranking processes as being very necessary in differentiating between efficient and non-efficient firms, which they believe is one of the most important decision making processes in equity markets.

Various authors or techniques rank portfolios in different ways. For example, Narayan et al. (2017) sort equity portfolios into deciles to which labels are given such as Loser portfolio or Winner portfolio. Thomasz and Bariviera (2013) examine the risk behavior of stock markets in 30 countries before and after the sub-prime crisis, and using a variety of risk indicators, they classify markets into high, medium, and low risk. Other authors use techniques such as quantile regression to classify observations into different quantiles according to characteristics such as risk or return (Koenker and Bassett 1978; Allen et al. 2009). An example from a non-equities perspective of ranking or classifying portfolios according to risk are credit ratings. For example, a rating of AAA ranks above a rating of AA. These credit ratings are not meant to be absolute measures of the risk of default but are instead meant to be ordinal rankings of the risk of a firm or bond in comparison to others at a stipulated point in time, and rating agencies insist that they are viewed in this manner (Cantor and Mann 2003; Amato and Furfine 2004).

We calculate parametric VaR, historical VaR, modified VaR and CVaR measures for each of the 10 years in our sample period for each country, and as mentioned above, these are grouped into total, crisis, and non-crisis periods. The ten industries are ranked from 1 to 10 for each metric for each period. A ranking of 1 represents lowest risk and a ranking of 10 represents highest risk. For example, per Appendix A, Table A1, Healthcare has the lowest CVaR for China in the crisis period and thus Healthcare receives a ranking of 1 for that period (crisis) and for that metric (CVaR). We use a nonparametric Spearman rank correlation coefficient to measure correlation in industry rankings between metrics, for the different countries and for the crisis and non-crisis periods. Nonparametric ranking methods such as Spearman are ideal where there are not a large number of observations in each group, such as in our case where we have ten observations in each of our categories (the rankings for each of the ten industries).

The Spearman test measures correlation between two sets of ranked data by the rank correlation coefficient $r_{s}$, which yields values between $r_{s}=1$ (perfect positive correlation) and $r_{s}=-1$ (perfect inverse correlation). In Equation (4) below, $n=$ the number of ranked items (in our case the number of industries), and $d=$ difference in ranking for each paired item (for example the ranking provided for manufacturing by $\mathrm{CVaR}$ as compared to the ranking provided for manufacturing by parametric $\mathrm{VaR})$. A $t$ test is then undertaken with $t$ calculated as per Equation (5), and the level of significance then determined from $t$ tables.

$$
\begin{gathered}
r_{s}=1-\frac{6 \sum d^{2}}{n\left(n^{2}-1\right)} \\
t=\frac{r_{s}}{\sqrt{\left(1-r_{s}^{2}\right)} /(n-2)}
\end{gathered}
$$




\subsection{Optimization Methodology}

The relative risk of an asset is a fundamental component of the capital asset pricing model (CAPM). However, the model is not just a straightforward ranking of risk, but the CAPM Beta reflects how risky an asset is compared to overall market risk and is a function of the volatility of the asset (or assets) and the market, and the correlation between the two. A straightforward ordinal ranking of industry equity portfolio risk could be critiqued on the basis that it does not account for covariance between portfolios. Therefore, to account for this covariance, we not only undertake the rankings using a straightforward risk-based ordinal measure, but we also use a Markowitz (1952) type model to rank each industry according to its contribution to an all-industry portfolio, using the each of the various metrics as risk optimizers. The standard Markowitz model uses standard deviation-return (accounting for covariance between assets) or variance-return, whereas we compare portfolio contribution using VaR-return (for each of parametric, historical, and modified VaR) and CVaR-return. Returns are actual returns and are therefore constant across all the risk metrics. This approach will show whether the relative contribution (ordinal ranking) of industries changes depending on which of these VaR or CVaR metrics is used. The Markowitz model is well known, and a detailed exposition on the model which is beyond the scope of this paper, can be found in Markowitz (1952). We do however provide key equations below and suffice it to say that the only important change we make is to replace standard deviation with each of the risk metrics that we examine in this study.

The Markowitz model optimizes portfolios by generating an efficient frontier for selected levels of return, which minimizes the risk of the portfolio, and then calculates the percentage contribution of each item (in our case industries) to the efficient portfolio. Risk (which is represented in the example below by standard deviation $\sigma$ ) of portfolio $x$ is minimized in Equation (6) where $x_{i k}$ are optimal portfolio weights of sectors $i$ and $k$ and $\sigma_{i k}$ is the covariance between returns of industry sectors $i$ and $k$ (and any other sectors), subject to various constraints (Equations (7)-(9)). These constraints include that the sum of the optimal weightings of the sectors in the portfolio must add to $100 \%$ (Equation (7)), the combined returns of the sectors $\left(r_{i}\right)$ must equal the expected return of the portfolio (Equation (8)), and the weightings for each sector must be positive (Equation (9)).

$$
\min _{x} \sum_{i=1}^{n} \sum_{k=1}^{n} \sigma_{i k} x_{i} x_{k}
$$

Subject to the following constraints

$$
\begin{gathered}
\sum_{i=1}^{n} x_{i}=1 \\
\sum_{i=1}^{n} \operatorname{IE}\left[r_{i}\right] x_{i}=r_{p} \\
0 \leq x_{i k}
\end{gathered}
$$

Varying the expected returns is what creates the efficient frontier. In our case, we create ten return scenarios, with the highest point being maximum return (the maximum return that can be generated from the portfolio), the lowest return point being the portfolio return where risk is minimized, and the remaining points being equidistant returns between the maximum and minimum return points. We then minimize the risk and create optimal weightings at each return point per Equations (6)-(9) for each of the sectors and use the average of these optimal weightings for each sector to generate the rankings for each industry.

\section{Results}

Our research questions relate to whether there are similarities between the metrics in how they rank industry risk in each of the countries, and whether this stays consistent across the periods (crisis, non-crisis and total). For example, would an industry which is ranked highest (lowest) risk using 
the parametric VaR metric, also have the highest (lowest) risk using CVaR or historical VaR metrics? The highest/lowest risk industries are shown by metric in Table 1 for each country and for each of the periods (total ten-year period, non-crisis period, crisis period). As an illustration we only show the $95 \%$ confidence level for this table, but detailed information on VaR and CVaR and rankings at both 95\% and 99\% levels is contained in Appendix A. Given the high number of potential combinations, we have aggregated the figures at a regional level for the six ASEAN countries in Table 1.

Table 1. Industries with highest/lowest risk (95\% confidence).

\begin{tabular}{|c|c|c|c|c|c|c|}
\hline & Total Period & Non-Crisis & Crisis & Total Period & Non-Crisis & Crisis \\
\hline Hist VaR & Lowest Risk & Lowest Risk & Lowest Risk & Highest Risk & Highest Risk & Highest Risk \\
\hline China & Oil \& Gas & Oil \& Gas & Healthcare & Telecom & Telecom & Telecom \\
\hline Japan & Healthcare & Healthcare & Healthcare & Oil \& Gas & Oil \& Gas & Oil \& Gas \\
\hline ASEAN & Goods & Financials & Goods & Technol. & Technol. & Technol. \\
\hline US & Goods & Goods & Goods & Materials & Materials & Financials \\
\hline Para VaR & Lowest Risk & Lowest Risk & Lowest Risk & Highest Risk & Highest Risk & Highest Risk \\
\hline China & Healthcare & Oil \& Gas & Healthcare & Telecom & Telecom & Telecom \\
\hline Japan & Healthcare & Services & Utilities & Oil \& Gas & Utilities & Oil \& Gas \\
\hline ASEAN & Goods & Financials & Goods & Technol. & Technol. & Technol. \\
\hline US & Goods & Goods & Goods & Financials & Oil \& Gas & Financials \\
\hline Mod VaR & Lowest Risk & Lowest Risk & Lowest Risk & Highest Risk & Highest Risk & Highest Risk \\
\hline China & Utilities & Utilities & Healthcare & Telecom & Telecom & Telecom \\
\hline Japan & Healthcare & Healthcare & Healthcare & Oil \& Gas & Utilities & Financials \\
\hline ASEAN & Goods & Financials & Goods & Technol. & Technol. & Technol. \\
\hline US & Goods & Goods & Goods & Financials & Materials & Financials \\
\hline CVaR & Lowest Risk & Lowest Risk & Lowest Risk & Highest Risk & Highest Risk & Highest Risk \\
\hline China & Utilities & Utilities & Healthcare & Telecom & Telecom & Telecom \\
\hline Japan & Healthcare & Healthcare & Healthcare & Oil \& Gas & Oil \& Gas & Financials \\
\hline ASEAN & Financials & Financials & Goods & Technol. & Technol. & Technol. \\
\hline US & Goods & Goods & Goods & Materials & Financials & Financials \\
\hline
\end{tabular}

Healthcare dominates as the lowest risk across all the risk metrics in Japan, and Consumer Goods and Financials in the ASEAN Countries. In China, there is some switching in lowest risk between Healthcare, Oil and Gas, and Utilities depending on the period and the metric. From a highest risk viewpoint, in all periods Telecommunications is the highest by all risk measures in China. In Japan, Oil and Gas is fairly dominant as the highest risk across the board. In the ASEAN region Technology is consistently dominant across all metrics in all periods.

As an illustration of the high degree of similarity between metrics, we compare CVaR to parametric VaR (95\%) in Figure 1 for the US and for Asia as whole (combination of China, Japan, and ASEAN). Although the figure shows only summary data, we have provided more detailed data in the ensuing tables and in Appendix A. While there are some minor differences, there is substantial similarity between the rankings.

To test the research questions, we need to ascertain whether, taking the rankings of all ten industries into account, the differences between metrics are significant or not. First, we rank the industries for each country (1 being the lowest risk and 10 being the highest risk) for each risk metric (parametric VaR, historical VaR, modified VaR and CVaR).

We compare each metric to each other metric for each country over each of the three periods. In Table 2 we show the ranking correlation between the different metrics at 95\% confidence level (and Table 3 at 99\% confidence level) using a Spearman ranking correlation coefficient (further details of this method are provided in the materials and methods discussion in Section 2). So, for example, in column 3 of Table 2, we take the rankings each of the industries from lowest to highest risk using parametric VaR and the do the same using historical VaR and then compare these ranking outcomes. In these particular tables we have separated the 6 ASEAN countries to illustrate any differences or similarities between them). Overall, there are 180 comparisons in Table 2 (eighteen columns $\times$ ten 
countries) of metric pairings. In the vast majority of cases (in 170 of the 180) comparisons in Table 2 there is high industry ranking correlation at $99 \%$ significance between all the metrics with nine of the remaining 10 pairings having ranking correlation of $95 \%$ significance. Thus, with very few exceptions, industries that are ranked highest/lowest risk by parametric $\mathrm{VaR}$, are also ranked highest/lowest risk by historical $\mathrm{VaR}$, modified $\mathrm{VaR}$ and $\mathrm{CVaR}$ with significant similarity across all the periods (crisis, non-crisis and total). In Table 3 (99\% VaR and CVaR), there are a further 180 pairings. Although the vast majority of pairings (154 out of 180) have high ranking correlation (99\% significance), this is lower than for Table 2. This shows that there is slightly less association between the more extreme $99 \% \mathrm{VaR}$ and CVaR metrics, than was found for the 95\% VaR and CVaR metrics. Nonetheless, the overall level of association between the metrics is high for both tables.

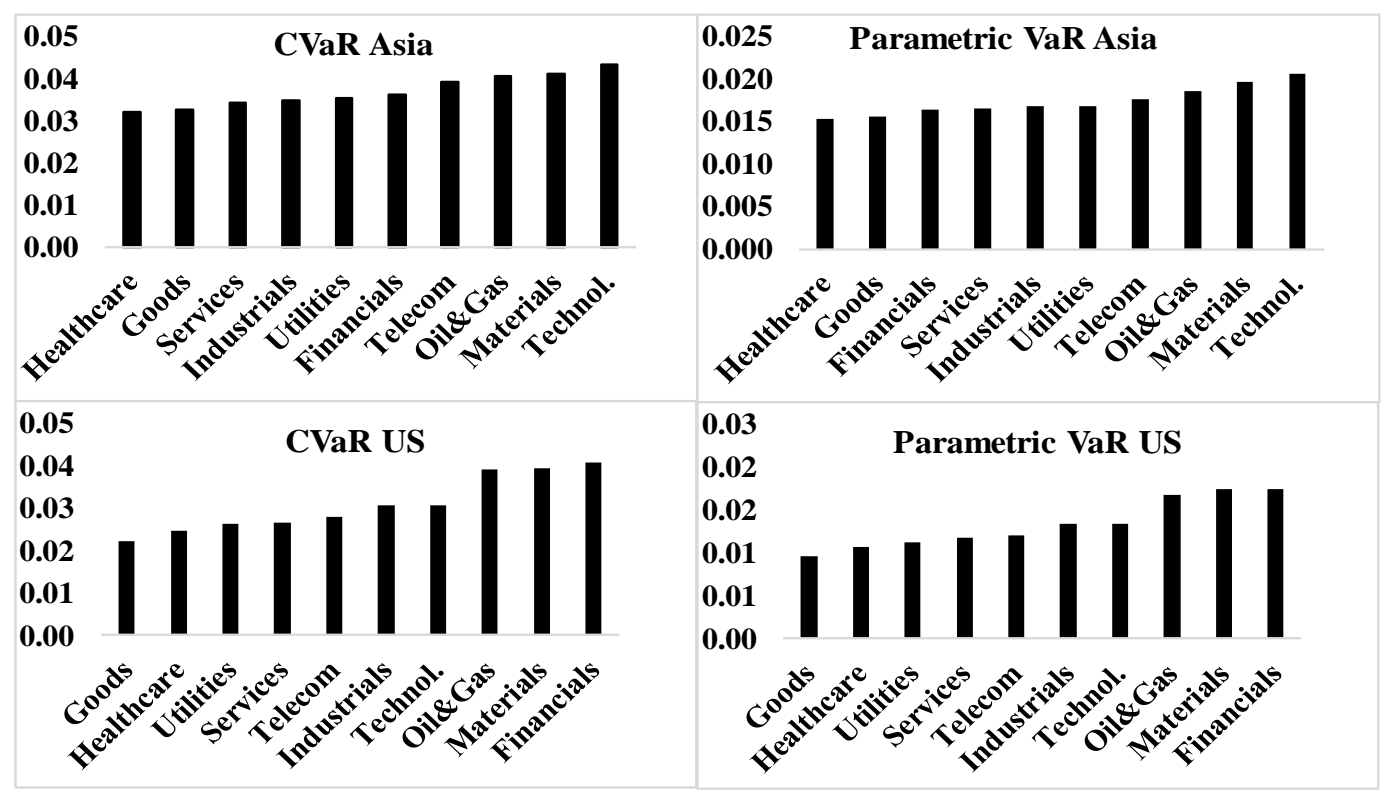

Figure 1. Total period CVaR and Parametric VaR (95\%).

As has already been mentioned, to account for covariance between industry portfolios, we use a Markowitz (1952) type model to measure the ordinal rankings of contributions to a combined industry portfolio, when using each of the metrics (parametric VaR, historical VaR, modified VaR or CVaR) as risk optimizers. The results are illustrated in Table 4 (only for 95\% VaR and CVaR to avoid excessive reporting), where we again see significant similarity between the metrics, with 66 out of 72 of the comparisons showing high correlation between the metrics at $99 \%$ significance and 5 of the remaining 6 at 95\% significance. This means that no matter which metric is used in the optimization, the outcome will be significantly similar in terms of which industry makes the highest contribution to the portfolio, i.e., the ordinal rankings will be substantially the same. 
Table 2. Ranking correlation of industries between different metrics 95\% VaR.

\begin{tabular}{|c|c|c|c|c|c|c|c|c|c|c|}
\hline 95\% VaR & & $\begin{array}{c}\text { Para. vs. His. VaR } \\
\text { Total }\end{array}$ & $\begin{array}{l}\text { Para. vs. His. VaR } \\
\text { Non-Crisis }\end{array}$ & $\begin{array}{c}\text { Para. vs. His. VaR } \\
\text { Crisis }\end{array}$ & $\begin{array}{l}\text { Para. vs. CVaR } \\
\text { Total }\end{array}$ & $\begin{array}{l}\text { Para. vs. CVaR } \\
\text { Non-Crisis }\end{array}$ & $\begin{array}{l}\text { Para. vs. CVaR } \\
\text { Crisis }\end{array}$ & $\begin{array}{c}\text { His. VaR vs. CVaR } \\
\text { Total }\end{array}$ & $\begin{array}{l}\text { His. VaR vs. CVaR } \\
\text { Non-Crisis }\end{array}$ & $\begin{array}{c}\text { His. VaR vs. CVaR } \\
\text { Crisis }\end{array}$ \\
\hline US & $\mathrm{r}$ & $\underset{* *}{0.988}$ & $\underset{* *}{0.988}$ & $\underset{* * *}{0.988}$ & $\begin{array}{c}1.000 \\
* *\end{array}$ & 1.000 & 0.952 & 0.988 & 0.988 & 0.964 \\
\hline & sig. & $* *$ & $* *$ & ** & ** & $* *$ & $* *$ & $* *$ & $* *$ & $* *$ \\
\hline China & $\mathrm{r}$ & 0.830 & 0.988 & 0.842 & 0.782 & 0.830 & 0.745 & 0.661 & 0.891 & 0.539 \\
\hline & sig. & ${ }^{* *}$ & ${ }^{* *}$ & ${ }^{* *}$ & ${ }^{* *}$ & ${ }^{* *}$ & ${ }^{*}$ & ${ }^{*}$ & ${ }^{* *}$ & - \\
\hline Japan & $\mathrm{r}$ & 0.976 & 0.964 & 0.988 & 0.988 & 0.952 & 0.964 & 0.964 & 0.952 & 0.976 \\
\hline & sig. & $* *$ & $* *$ & $* *$ & $* *$ & $* *$ & $* *$ & ** & ** & ** \\
\hline Indonesia & $\mathrm{r}$ & 0.976 & 0.976 & 0.927 & 1.000 & 0.988 & 0.939 & 0.976 & 0.988 & 0.794 \\
\hline & sig. & $* *$ & $* *$ & ${ }^{* *}$ & $*^{* *}$ & ${ }^{* *}$ & ${ }^{* *}$ & ${ }^{* *}$ & ${ }^{* *}$ & $* *$ \\
\hline Malaysia & $\begin{array}{c}\mathrm{r} \\
\text { sig. }\end{array}$ & 0.988 & $\underset{* *}{0.988}$ & $\underset{* * *}{0.976}$ & 1.000 & $\underset{* *}{0.939}$ & $\underset{* *}{0.976}$ & $\underset{* *}{0.988}$ & $\underset{* *}{0.952}$ & $\underset{* *}{0.927}$ \\
\hline Philippines & $\mathrm{r}$ & 0.933 & 0.767 & 0.950 & 0.983 & 0.967 & 0.967 & 0.967 & 0.883 & 0.917 \\
\hline & $\begin{array}{c}\text { sig. } \\
\mathrm{r}\end{array}$ & $* *$ & ${ }^{*}$ & ${ }^{* *}$ & ${ }^{* *}$ & ${ }^{* *}$ & ** & ${ }^{* *}$ & ** & ** \\
\hline Singapore & $\begin{array}{c}\mathrm{r} \\
\text { sig. }\end{array}$ & $\underset{* *}{0.988}$ & 1.000 & 0.952 & $\underset{* *}{0.952}$ & $\underset{* *}{0.988}$ & 0.976 & $\underset{* *}{0.964}$ & $\underset{* *}{0.988}$ & $\underset{* *}{0.952}$ \\
\hline Thailand & $\begin{array}{c}\mathrm{r} \\
\mathrm{sig} .\end{array}$ & 0.976 & 0.939 & 0.879 & 1.000 & $\underset{* *}{0.988}$ & 0.964 & 0.976 & $\underset{* *}{0.952}$ & 0.855 \\
\hline Vietnam & $\mathrm{r}$ & 0.997 & 0.830 & 0.648 & 0.926 & 0.927 & 0.891 & 0.907 & 0.842 & 0.733 \\
\hline & sig. & $* *$ & $* *$ & * & $* *$ & $* *$ & $* *$ & $* *$ & $* *$ & * \\
\hline ASEAN & $\begin{array}{c}\mathrm{r} \\
\text { sig. }\end{array}$ & $\underset{* *}{0.988}$ & $\underset{* *}{0.964}$ & $\stackrel{0.952}{* *}$ & $\underset{* *}{0.976}$ & $\underset{* *}{0.988}$ & 0.988 & $\underset{* *}{0.964}$ & $\underset{* *}{0.988}$ & 0.927 \\
\hline $95 \%$ VaR & & $\begin{array}{l}\text { Mod. vs. Para. VaR } \\
\text { Total }\end{array}$ & $\begin{array}{c}\text { Mod. vs. Para. VaR } \\
\text { Non-Crisis }\end{array}$ & $\begin{array}{c}\text { Mod. vs. Para VaR } \\
\text { Crisis }\end{array}$ & $\begin{array}{l}\text { Mod. vs. His. VaR } \\
\text { Total }\end{array}$ & $\begin{array}{c}\text { Mod. vs. His. VaR } \\
\text { Non-Crisis }\end{array}$ & $\begin{array}{l}\text { Mod. vs. His. VaR } \\
\text { Crisis }\end{array}$ & $\begin{array}{c}\text { Mod. VaR vs. CVaR } \\
\text { Total }\end{array}$ & $\begin{array}{l}\text { Mod. VaR vs. CVaR } \\
\text { Non-Crisis }\end{array}$ & $\begin{array}{l}\text { Mod. VaR vs. CVaR } \\
\text { Crisis }\end{array}$ \\
\hline US & $\begin{array}{c}\mathrm{r} \\
\text { sig. }\end{array}$ & $\underset{* *}{1.000}$ & $\underset{* *}{0.952}$ & $\underset{* *}{0.964}$ & $\underset{* *}{1.000}$ & $\underset{* *}{0.964}$ & $\underset{* *}{0.964}$ & 1.000 & $\underset{* *}{0.952}$ & $\underset{* *}{0.939}$ \\
\hline China & $\begin{array}{c}\mathrm{r} \\
\text { sig. }\end{array}$ & $\underset{* *}{0.891}$ & $\underset{* *}{0.939}$ & $\underset{* *}{0.867}$ & $\underset{* *}{0.770}$ & $\underset{* *}{0.939}$ & $\underset{*}{0.758}$ & $\underset{* *}{0.952}$ & $\underset{* *}{0.927}$ & $\underset{* *}{0.855}$ \\
\hline Japan & $\begin{array}{c}\mathrm{r} \\
\text { sig. }\end{array}$ & $\underset{* *}{0.891}$ & $\underset{* *}{0.976}$ & $\underset{* *}{0.964}$ & $\stackrel{0.891}{* *}$ & $\underset{* *}{0.976}$ & $\underset{* *}{0.976}$ & $\underset{* *}{0.939}$ & $\underset{* *}{0.976}$ & $\underset{* *}{1.000}$ \\
\hline Indonesia & $\begin{array}{c}\mathrm{r} \\
\text { sig. }\end{array}$ & $\underset{* *}{0.818}$ & $\stackrel{0.806}{* *}$ & $\stackrel{0.891}{* *}$ & $\underset{* *}{0.745}$ & $\stackrel{0.806}{* *}$ & $\underset{* *}{0.782}$ & $\underset{* *}{0.818}$ & $\underset{* *}{0.842}$ & $\stackrel{0.879}{* *}$ \\
\hline Malaysia & $\begin{array}{c}\mathrm{r} \\
\text { sig. }\end{array}$ & $\underset{* *}{0.952}$ & $\stackrel{0.830}{* *}$ & $\stackrel{0.988}{* *}$ & $\stackrel{0.927}{* *}$ & $\stackrel{0.830}{* *}$ & $\underset{* *}{0.952}$ & $\underset{* *}{0.952}$ & $\underset{*}{0.758}$ & $\stackrel{0.988}{* *}$ \\
\hline Philippines & $\begin{array}{c}\mathrm{r} \\
\text { sig. }\end{array}$ & $\underset{* *}{0.873}$ & $\stackrel{0.861}{* *}$ & $\stackrel{0.933}{* *}$ & $\underset{* *}{0.873}$ & $\stackrel{0.861}{* *}$ & $\underset{* *}{0.933}$ & $\underset{* *}{0.848}$ & $\underset{* *}{0.861}$ & $\stackrel{0.897}{* *}$ \\
\hline Singapore & $\begin{array}{c}\mathrm{r} \\
\text { sig. }\end{array}$ & $\underset{* *}{0.879}$ & $\underset{* *}{0.988}$ & $\stackrel{0.867}{* *}$ & $\stackrel{0.891}{* *}$ & $\underset{* *}{0.988}$ & $\underset{* *}{0.818}$ & $\stackrel{0.952}{* *}$ & $\underset{* *}{0.976}$ & $\stackrel{0.867}{* *}$ \\
\hline Thailand & $\begin{array}{c}\mathrm{r} \\
\text { sig. }\end{array}$ & $\underset{* *}{0.830}$ & $\begin{array}{c}0.745 \\
*\end{array}$ & $\underset{* *}{0.770}$ & $\underset{* *}{0.915}$ & $\begin{array}{c}0.745 \\
*\end{array}$ & $\underset{* *}{0.903}$ & $\underset{* *}{0.830}$ & $\underset{* *}{0.770}$ & $\underset{* *}{0.782}$ \\
\hline Vietnam & $\begin{array}{c}\mathrm{r} \\
\text { sig. }\end{array}$ & $\underset{* *}{0.976}$ & $\underset{* *}{0.964}$ & $\underset{* *}{0.939}$ & $\underset{* *}{0.952}$ & $\underset{* *}{0.964}$ & $\underset{* *}{0.903}$ & $\underset{* *}{0.891}$ & $\underset{* *}{0.855}$ & $\underset{* *}{0.830}$ \\
\hline ASEAN & $\begin{array}{c}\mathrm{r} \\
\text { sig. }\end{array}$ & $\underset{* *}{0.927}$ & $\underset{* *}{0.915}$ & $\underset{* *}{0.952}$ & $\underset{* *}{0.964}$ & $\underset{* *}{0.915}$ & $\underset{* *}{0.952}$ & $\begin{array}{c}0.891 \\
* * \\
\end{array}$ & $\underset{* *}{0.952}$ & $\underset{* *}{0.952}$ \\
\hline
\end{tabular}

$\mathrm{r}$ is the industry ranking correlation statistic between metrics, with * denoting significance at the $95 \%$ confidence level and ${ }^{* *}$ denoting significance at the $99 \%$ confidence level. Abbreviations: Para (parametric); Mod (modified); His (historical). 
Table 3. Ranking correlation of industries between different metrics $99 \%$ VaR.

\begin{tabular}{|c|c|c|c|c|c|c|c|c|c|c|}
\hline 99\% VaR & & $\begin{array}{c}\text { Para. vs. His. VaR } \\
\text { Total }\end{array}$ & $\begin{array}{l}\text { Para. vs. His. VaR } \\
\text { Non-Crisis }\end{array}$ & $\begin{array}{l}\text { Para. vs. His. VaR } \\
\text { Crisis }\end{array}$ & $\begin{array}{l}\text { Para. vs. CVaR } \\
\text { Total }\end{array}$ & $\begin{array}{l}\text { Para. vs. CVaR } \\
\text { Non-Crisis }\end{array}$ & $\begin{array}{l}\text { Para. vs. CVaR } \\
\text { Crisis }\end{array}$ & $\begin{array}{l}\text { His. VaR vs. CVaR } \\
\text { Total }\end{array}$ & $\begin{array}{l}\text { His. VaR vs. CVaR } \\
\text { Non-Crisis }\end{array}$ & $\begin{array}{l}\text { His. VaR vs. CVaR } \\
\text { Crisis }\end{array}$ \\
\hline US & $\mathrm{r}$ & 0.988 & 0.988 & 0.915 & 0.988 & 0.988 & 0.952 & 0.976 & 1.000 & 0.939 \\
\hline & sig. & $* *$ & $* *$ & $* *$ & $* *$ & $* *$ & $* *$ & $* *$ & $* *$ & $* *$ \\
\hline China & $\mathrm{r}$ & 0.600 & 0.697 & 0.709 & 0.648 & 0.552 & 0.697 & 0.952 & 0.927 & 0.867 \\
\hline & sig. & & ${ }^{*}$ & & ${ }^{*}$ & & ${ }^{*}$ & $* *$ & $* *$ & $* *$ \\
\hline Japan & $\mathrm{r}$ & 0.976 & 0.927 & 0.952 & 0.952 & 0.952 & 0.915 & 0.988 & 0.952 & 0.976 \\
\hline & sig. & $* *$ & $* *$ & $* *$ & $* *$ & $* *$ & $* *$ & $* *$ & $* *$ & ** \\
\hline Indonesia & $\mathrm{r}$ & 0.867 & 0.988 & 0.867 & 0.867 & 0.939 & 0.842 & 0.964 & 0.915 & 0.879 \\
\hline & sig. & $* *$ & $* *$ & $*^{* *}$ & $* *$ & ${ }^{* *}$ & ${ }^{* *}$ & $* *$ & $* *$ & $* *$ \\
\hline Malaysia & $\mathrm{r}$ & 0.988 & 0.891 & 0.915 & 0.964 & 0.927 & 0.855 & 0.988 & 0.939 & 0.867 \\
\hline & sig. & $* *$ & $* *$ & $* *$ & $* *$ & $* *$ & $* *$ & ${ }^{* *}$ & $* *$ & $* *$ \\
\hline Philippines & $\begin{array}{c}\mathrm{r} \\
\text { sig. }\end{array}$ & $\underset{* *}{0.970}$ & $\underset{* *}{0.970}$ & $\underset{* *}{0.915}$ & $\underset{* *}{0.909}$ & $\underset{* *}{0.982}$ & 0.867 & 0.879 & $\underset{* *}{0.952}$ & $\underset{* *}{0.879}$ \\
\hline Singapore & $\mathrm{r}$ & 0.988 & 1.000 & 0.927 & 0.952 & 0.927 & 0.964 & 0.964 & 0.964 & 0.927 \\
\hline & sig. & $* *$ & $* *$ & $* *$ & $* *$ & $* *$ & $* *$ & $* *$ & $* *$ & $* *$ \\
\hline Thailand & $\begin{array}{c}\mathrm{r} \\
\mathrm{sig}\end{array}$ & $\underset{* *}{0.952}$ & $\underset{* *}{0.952}$ & 0.903 & 0.988 & 0.915 & 0.891 & 0.964 & $\underset{* *}{0.964}$ & $\underset{* *}{0.988}$ \\
\hline Vietnam & $\mathrm{r}$ & 0.939 & 0.867 & 0.903 & 0.939 & 0.830 & 0.915 & 0.952 & 0.964 & 0.994 \\
\hline & sig. & $* *$ & $* *$ & $* *$ & $* *$ & $* *$ & $* *$ & $* *$ & $* *$ & $* *$ \\
\hline ASEAN & $\begin{array}{c}\mathrm{r} \\
\text { sig. }\end{array}$ & $\begin{array}{c}0.964 \\
* *\end{array}$ & $\underset{* *}{0.988}$ & $\stackrel{0.891}{* *}$ & $\underset{* *}{0.939}$ & $\underset{* *}{0.976}$ & $\underset{* *}{0.927}$ & $\underset{* *}{0.976}$ & $\underset{* *}{0.988}$ & 0.976 \\
\hline $99 \%$ VaR & & $\begin{array}{l}\text { Mod. vs. Para. VaR } \\
\text { Total }\end{array}$ & $\begin{array}{l}\text { Mod. vs. Para. VaR } \\
\text { Non-Crisis }\end{array}$ & $\begin{array}{l}\text { Mod. vs. Para VaR } \\
\text { Crisis }\end{array}$ & $\begin{array}{l}\text { Mod. vs. His. VaR } \\
\text { Total }\end{array}$ & $\begin{array}{c}\text { Mod. vs. His. VaR } \\
\text { Non-Crisis }\end{array}$ & $\begin{array}{l}\text { Mod. vs. His. VaR } \\
\text { Crisis }\end{array}$ & $\begin{array}{c}\text { Mod. VaR vs. CVaR } \\
\text { Total } \\
\end{array}$ & $\begin{array}{l}\text { Mod. VaR vs. CVaR } \\
\text { Non-Crisis }\end{array}$ & $\begin{array}{l}\text { Mod. VaR vs. CVaR } \\
\text { Crisis }\end{array}$ \\
\hline US & $\begin{array}{c}\mathrm{r} \\
\text { sig. }\end{array}$ & $\underset{* *}{0.733}$ & $\underset{* *}{0.927}$ & 0.600 & $\underset{* *}{0.758}$ & $\underset{* *}{0.903}$ & $\underset{* *}{0.782}$ & $\underset{* *}{0.758}$ & $\underset{* *}{0.903}$ & $\underset{*}{0.745}$ \\
\hline China & $\begin{array}{c}\mathrm{r} \\
\text { sig. }\end{array}$ & $\begin{array}{c}0.455 \\
-\end{array}$ & $\begin{array}{c}0.067 \\
-\end{array}$ & $\underset{*}{0.661}$ & $\underset{* *}{0.855}$ & $\begin{array}{c}0.067 \\
-\end{array}$ & $\underset{* *}{0.867}$ & $\underset{* *}{0.927}$ & $\underset{* *}{0.830}$ & $\underset{* *}{0.818}$ \\
\hline Japan & $\begin{array}{c}\mathrm{r} \\
\text { sig. }\end{array}$ & $\begin{array}{c}0.648 \\
*\end{array}$ & $\underset{*}{0.636}$ & $\underset{* *}{0.867}$ & $\underset{*}{0.685}$ & $\underset{*}{0.636}$ & $\underset{* *}{0.927}$ & $\stackrel{0.697}{*}$ & $\underset{*}{0.745}$ & $\underset{* *}{0.939}$ \\
\hline Indonesia & $\begin{array}{c}\mathrm{r} \\
\text { sig. }\end{array}$ & $\underset{* *}{0.927}$ & $\underset{* *}{0.915}$ & $\stackrel{0.842}{*}$ & $\underset{* *}{0.842}$ & $\underset{* *}{0.915}$ & $\underset{* *}{0.915}$ & $\underset{* *}{0.830}$ & $\underset{* *}{0.855}$ & $\underset{* *}{0.855}$ \\
\hline Malaysia & $\begin{array}{c}\mathrm{r} \\
\text { sig. }\end{array}$ & $\begin{array}{c}0.733 \\
*\end{array}$ & $\underset{* *}{0.842}$ & $\begin{array}{c}0.394 \\
-\end{array}$ & $\underset{*}{0.745}$ & $\underset{* *}{0.842}$ & $\begin{array}{c}0.285 \\
-\end{array}$ & $\underset{* *}{0.806}$ & $\underset{* *}{0.927}$ & $\begin{array}{c}0.576 \\
-\end{array}$ \\
\hline Philippines & $\begin{array}{c}\mathrm{r} \\
\text { sig. }\end{array}$ & $\underset{* *}{0.818}$ & $\underset{* *}{0.885}$ & $\underset{* *}{0.903}$ & $\underset{* *}{0.812}$ & $\underset{* *}{0.885}$ & $\stackrel{0.891}{* *}$ & $\underset{* *}{0.909}$ & $\underset{* *}{0.915}$ & $\underset{* *}{0.927}$ \\
\hline Singapore & $\begin{array}{c}\mathrm{r} \\
\text { sig. }\end{array}$ & $\underset{* *}{0.952}$ & $\underset{* *}{0.818}$ & $\begin{array}{c}0.879 \\
* *\end{array}$ & $\underset{* *}{0.915}$ & $\underset{* *}{0.818}$ & $\underset{* *}{0.806}$ & $\underset{* *}{0.976}$ & $\underset{* *}{0.964}$ & $\underset{* *}{0.939}$ \\
\hline Thailand & $\begin{array}{c}\mathrm{r} \\
\text { sig. }\end{array}$ & $\underset{* *}{0.818}$ & $\underset{* *}{0.867}$ & 0.624 & $\underset{* *}{0.891}$ & $\underset{* *}{0.867}$ & $\underset{*}{0.697}$ & $\underset{* *}{0.903}$ & $\underset{* *}{0.879}$ & $\begin{array}{c}0.709 \\
*\end{array}$ \\
\hline Vietnam & $\begin{array}{c}\mathrm{r} \\
\text { sig. }\end{array}$ & $\begin{array}{c}0.903 \\
* *\end{array}$ & $\underset{* *}{0.903}$ & $\begin{array}{c}0.988 \\
* *\end{array}$ & $\begin{array}{c}0.733 \\
*\end{array}$ & $\underset{* *}{0.903}$ & $\underset{* *}{0.939}$ & $\underset{* *}{0.855}$ & $\underset{* *}{0.927}$ & $\underset{* *}{0.927}$ \\
\hline ASEAN & $\begin{array}{c}\mathrm{r} \\
\text { sig. }\end{array}$ & $\underset{* *}{0.903}$ & $\underset{* *}{0.806}$ & $\begin{array}{c}0.939 \\
* *\end{array}$ & $\underset{* *}{0.903}$ & $\underset{* *}{0.806}$ & $\begin{array}{c}0.782 \\
* * \\
\end{array}$ & $\begin{array}{c}0.879 \\
* * \\
\end{array}$ & $\begin{array}{c}0.867 \\
* * \\
\end{array}$ & $\begin{array}{c}0.830 \\
* * \\
\end{array}$ \\
\hline
\end{tabular}

$\mathrm{r}$ is the industry ranking correlation statistic between metrics, with * denoting significance at the $95 \%$ confidence level and ${ }^{* *}$ denoting significance at the $99 \%$ confidence level. Abbreviations: Para (parametric); Mod (modified); His (historical). 
Table 4. Markowitz model ranking correlation of industries between different metrics (95\% VaR and CVaR).

\begin{tabular}{|c|c|c|c|c|c|c|c|c|c|c|}
\hline 95\% VaR & & $\begin{array}{c}\text { Para. vs. } \\
\text { His. } \\
\text { Total }\end{array}$ & $\begin{array}{c}\text { Para. vs. } \\
\text { His. } \\
\text { Non-Crisis }\end{array}$ & $\begin{array}{c}\text { Para. vs. } \\
\text { His. } \\
\text { Crisis }\end{array}$ & $\begin{array}{c}\text { His. vs. } \\
\text { CVaR } \\
\text { Total }\end{array}$ & $\begin{array}{l}\text { His. vs. } \\
\text { CVaR } \\
\text { Non-Crisis }\end{array}$ & $\begin{array}{c}\text { His. vs. } \\
\text { CVaR } \\
\text { Crisis }\end{array}$ & $\begin{array}{c}\text { Para. vs. } \\
\text { CVaR } \\
\text { Total }\end{array}$ & $\begin{array}{c}\text { Para. vs. } \\
\text { CVaR } \\
\text { Non-Crisis }\end{array}$ & $\begin{array}{c}\text { Para. vs. } \\
\text { CVaR } \\
\text { Crisis }\end{array}$ \\
\hline US & $\begin{array}{c}\mathrm{R} \\
\text { sig. }\end{array}$ & $\begin{array}{c}0.764 \\
*\end{array}$ & $\underset{* *}{0.812}$ & $\underset{* *}{0.958}$ & $\underset{* *}{0.812}$ & $\underset{* *}{0.812}$ & $\underset{* *}{0.958}$ & $\underset{* *}{0.988}$ & $\underset{* *}{1.000}$ & $\underset{* *}{1.000}$ \\
\hline China & $\begin{array}{c}\mathrm{R} \\
\text { sig. }\end{array}$ & $\underset{* *}{0.988}$ & $\underset{* *}{0.988}$ & $\underset{* *}{1.000}$ & $\underset{* *}{0.927}$ & $\underset{* *}{0.952}$ & $\underset{* *}{0.976}$ & $\underset{* *}{0.952}$ & $\underset{* *}{0.976}$ & $\underset{* *}{0.976}$ \\
\hline Japan & $\begin{array}{c}\mathrm{R} \\
\text { sig. }\end{array}$ & $\underset{* *}{1.000}$ & $\underset{* *}{0.976}$ & $\underset{* *}{0.988}$ & $\underset{* *}{0.988}$ & $\underset{* *}{0.988}$ & $\underset{* *}{0.994}$ & $\underset{* *}{0.988}$ & $\underset{* *}{0.988}$ & $\begin{array}{c}0.982 \\
* *\end{array}$ \\
\hline ASEAN & $\begin{array}{c}\mathrm{R} \\
\text { sig. }\end{array}$ & $\begin{array}{c}0.988 \\
* *\end{array}$ & $\underset{* *}{1.000}$ & $\begin{array}{c}0.976 \\
* *\end{array}$ & $\begin{array}{c}0.988 \\
* *\end{array}$ & $\underset{* *}{1.000}$ & $\begin{array}{c}0.964 \\
* *\end{array}$ & $\begin{array}{c}0.976 \\
* *\end{array}$ & $\underset{* *}{1.000}$ & $\begin{array}{c}0.976 \\
* *\end{array}$ \\
\hline 95\% VaR & & $\begin{array}{l}\text { Para. vs. } \\
\text { Mod. } \\
\text { Total }\end{array}$ & $\begin{array}{l}\text { Para. vs. } \\
\text { Mod. } \\
\text { Non-Crisis }\end{array}$ & $\begin{array}{l}\text { Para. vs. } \\
\text { Mod. } \\
\text { Crisis }\end{array}$ & $\begin{array}{c}\text { His. vs. } \\
\text { Mod } \\
\text { Total }\end{array}$ & $\begin{array}{c}\text { His. vs. } \\
\text { Mod. } \\
\text { Non-Crisis }\end{array}$ & $\begin{array}{c}\text { His. vs. } \\
\text { Mod. } \\
\text { Crisis }\end{array}$ & $\begin{array}{l}\text { CVaR vs. } \\
\text { Mod. } \\
\text { Total }\end{array}$ & $\begin{array}{l}\text { CVaR vs. } \\
\text { Mod } \\
\text { Non-Crisis }\end{array}$ & $\begin{array}{c}\text { CVaR vs. } \\
\text { Mod } \\
\text { Crisis }\end{array}$ \\
\hline US & $\begin{array}{c}r \\
\text { sig. }\end{array}$ & $\underset{* *}{0.988}$ & $\begin{array}{c}0.697 \\
*\end{array}$ & $\underset{* *}{1.000}$ & $\underset{* *}{0.812}$ & $\begin{array}{c}0.462 \\
-\end{array}$ & $\underset{* *}{0.958}$ & $\underset{* *}{0.988}$ & $\underset{* *}{0.915}$ & 1.000 \\
\hline China & $\begin{array}{c}\mathrm{R} \\
\text { sig. }\end{array}$ & 1.000 & $\underset{* *}{0.952}$ & $\underset{* *}{0.988}$ & $\underset{* *}{0.988}$ & $\begin{array}{c}0.915 \\
* *\end{array}$ & $\underset{* *}{0.988}$ & $\underset{* *}{0.952}$ & $\underset{* *}{0.988}$ & $\underset{* *}{0.988}$ \\
\hline Japan & $\begin{array}{c}\mathrm{R} \\
\text { sig. }\end{array}$ & $\underset{* *}{1.000}$ & $\begin{array}{c}0.636 \\
*\end{array}$ & $\begin{array}{c}0.988 \\
* *\end{array}$ & $\underset{* *}{0.952}$ & $\begin{array}{c}0.624 \\
*\end{array}$ & $\underset{* *}{0.976}$ & $\underset{* *}{0.964}$ & $\begin{array}{c}0.624 \\
*\end{array}$ & $\underset{* *}{0.982}$ \\
\hline ASEAN & $\begin{array}{c}\mathrm{R} \\
\text { sig. }\end{array}$ & $\underset{* *}{0.952}$ & $\begin{array}{c}0.939 \\
* *\end{array}$ & $\underset{* *}{0.964}$ & $\begin{array}{c}0.927 \\
* *\end{array}$ & $\begin{array}{c}0.939 \\
* *\end{array}$ & $\begin{array}{c}0.939 \\
* *\end{array}$ & $\underset{* *}{0.915}$ & $\begin{array}{c}1.000 \\
* *\end{array}$ & $\underset{* *}{0.976}$ \\
\hline
\end{tabular}

$\mathrm{r}$ is the industry ranking correlation statistic between the metrics, with * denoting significance at the $95 \%$ confidence level and ${ }^{* *}$ denoting significance at the $99 \%$ confidence level. Abbreviations: Para (parametric); Mod (modified); His (historical). 


\section{Conclusions}

The research questions sought to ascertain whether there was association in industry risk rankings between metrics for each region across each period. We generally found very strong association which held across time periods and countries. This means that whether using VaR (parametric, modified, historical) or CVaR, we will arrive at similar conclusions about the relative risk of industries. Thus, contrary to most global studies on CVaR that were mentioned in Section 1, we find that for our study, $\mathrm{CVaR}$ does not yield much more information about relative industry risk than that which can be gained from historical or parametric VaR. This reflects that, although accounting for thick-tailed behavior may be relevant for risk quantification, it is not that relevant for ordinal measures. The finding supports that of Allen et al. (2012) who found similarities between parametric and nonparametric measures in measuring industry risk in Indonesia. This also tends to align with the common view that Asian markets have been relatively stable over the studied period, especially as compared to manty other global markets over the GFC, thus experiencing less swings in extreme tail risk.

Author Contributions: Data Collection, T.N.P. and D.H.V. Data analysis, T.N.P., R.J.P. and D.H.V. Supervision, D.H.V. Writing, R.J.P.

Funding: This research was funded by Ho Chi Minh City Open University, Vietnam', [Grant E2016.9.9.a. dated 12 September 2016].

Conflicts of Interest: The authors declare no conflict of interest. 


\section{Appendix}

Table A1. 95\% VaR and CVaR per industry: 2007-2016.

\begin{tabular}{|c|c|c|c|c|c|c|c|c|c|c|c|}
\hline & Hist. & Materials & Goods & Services & Financials & Health & Industrial & Oil \& Gas & Technol. & Telecom & Utilities \\
\hline \multirow{3}{*}{ China } & Total & 0.0327 & 0.0275 & 0.0300 & 0.0276 & 0.0271 & 0.0289 & 0.0262 & 0.0330 & 0.0388 & 0.0275 \\
\hline & Non-Crisis & 0.0272 & 0.0231 & 0.0260 & 0.0234 & 0.0239 & 0.0252 & 0.0206 & 0.0299 & 0.0328 & 0.0223 \\
\hline & Crisis & 0.0456 & 0.0377 & 0.0392 & 0.0373 & 0.0346 & 0.0376 & 0.0392 & 0.0401 & 0.0527 & 0.0397 \\
\hline \multirow{3}{*}{ Japan } & Total & 0.0266 & 0.0231 & 0.0212 & 0.0263 & 0.0188 & 0.0246 & 0.0283 & 0.0232 & 0.0210 & 0.0238 \\
\hline & Non-Crisis & 0.0240 & 0.0213 & 0.0184 & 0.0228 & 0.0179 & 0.0215 & 0.0253 & 0.0205 & 0.0196 & 0.0242 \\
\hline & Crisis & 0.0328 & 0.0273 & 0.0276 & 0.0347 & 0.0209 & 0.0319 & 0.0353 & 0.0296 & 0.0244 & 0.0229 \\
\hline \multirow{3}{*}{ ASEAN } & Total & 0.0295 & 0.0200 & 0.0229 & 0.0205 & 0.0223 & 0.0223 & 0.0279 & 0.0381 & 0.0219 & 0.0247 \\
\hline & Non-Crisis & 0.0258 & 0.0175 & 0.0198 & 0.0172 & 0.0195 & 0.0194 & 0.0234 & 0.0347 & 0.0195 & 0.0210 \\
\hline & Crisis & 0.0382 & 0.0257 & 0.0301 & 0.0282 & 0.0290 & 0.0292 & 0.0385 & 0.0461 & 0.0273 & 0.0333 \\
\hline \multirow{4}{*}{ US } & Total & 0.0267 & 0.0146 & 0.0179 & 0.0261 & 0.0164 & 0.0205 & 0.0260 & 0.0211 & 0.0184 & 0.0166 \\
\hline & Non-Crisis & 0.0215 & 0.0128 & 0.0148 & 0.0178 & 0.0153 & 0.0170 & 0.0212 & 0.0176 & 0.0142 & 0.0142 \\
\hline & Crisis & 0.0390 & 0.0187 & 0.0253 & 0.0454 & 0.0191 & 0.0286 & 0.0370 & 0.0290 & 0.0282 & 0.0224 \\
\hline & Para. VaR & Materials & Goods & Services & Financials & Health & Industrial & Oil \& Gas & Technol. & Telecom & Utilities \\
\hline \multirow{3}{*}{ China } & Total & 0.0352 & 0.0297 & 0.0333 & 0.0294 & 0.0290 & 0.0315 & 0.0297 & 0.0357 & 0.0396 & 0.0297 \\
\hline & Non-Crisis & 0.0299 & 0.0250 & 0.0291 & 0.0243 & 0.0255 & 0.0274 & 0.0233 & 0.0328 & 0.0346 & 0.0242 \\
\hline & Crisis & 0.0477 & 0.0408 & 0.0430 & 0.0412 & 0.0371 & 0.0413 & 0.0447 & 0.0425 & 0.0514 & 0.0425 \\
\hline \multirow{3}{*}{ Japan } & Total & 0.0294 & 0.0253 & 0.0235 & 0.0296 & 0.0210 & 0.0275 & 0.0314 & 0.0255 & 0.0241 & 0.0265 \\
\hline & Non-Crisis & 0.0256 & 0.0223 & 0.0193 & 0.0248 & 0.0194 & 0.0236 & 0.0272 & 0.0219 & 0.0221 & 0.0276 \\
\hline & Crisis & 0.0382 & 0.0323 & 0.0333 & 0.0406 & 0.0249 & 0.0367 & 0.0411 & 0.0341 & 0.0287 & 0.0240 \\
\hline \multirow{3}{*}{ ASEAN } & Total & 0.0312 & 0.0220 & 0.0248 & 0.0220 & 0.0255 & 0.0238 & 0.0311 & 0.0406 & 0.0235 & 0.0268 \\
\hline & Non-Crisis & 0.0272 & 0.0190 & 0.0208 & 0.0182 & 0.0213 & 0.0205 & 0.0259 & 0.0371 & 0.0206 & 0.0223 \\
\hline & Crisis & 0.0404 & 0.0289 & 0.0343 & 0.0309 & 0.0353 & 0.0313 & 0.0431 & 0.0489 & 0.0305 & 0.0375 \\
\hline \multirow{3}{*}{ US } & Total & 0.0286 & 0.0159 & 0.0193 & 0.0287 & 0.0177 & 0.0220 & 0.0275 & 0.0221 & 0.0198 & 0.0185 \\
\hline & Non-Crisis & 0.0218 & 0.0135 & 0.0156 & 0.0195 & 0.0159 & 0.0179 & 0.0221 & 0.0182 & 0.0151 & 0.0147 \\
\hline & Crisis & 0.0444 & 0.0214 & 0.0280 & 0.0504 & 0.0219 & 0.0315 & 0.0400 & 0.0310 & 0.0308 & 0.0273 \\
\hline
\end{tabular}


Table A1. Cont.

\begin{tabular}{|c|c|c|c|c|c|c|c|c|c|c|c|}
\hline & Mod. VaR & Materials & Goods & Services & Financials & Health & Industrial & Oil \& Gas & Technol. & Telecom & Utilities \\
\hline \multirow{3}{*}{ China } & Total & 0.0313 & 0.0253 & 0.0285 & 0.0267 & 0.0259 & 0.0271 & 0.0272 & 0.0318 & 0.0384 & 0.0250 \\
\hline & Non-Crisis & 0.0282 & 0.0228 & 0.0263 & 0.0233 & 0.0238 & 0.0249 & 0.0231 & 0.0304 & 0.0336 & 0.0218 \\
\hline & Crisis & 0.0424 & 0.0347 & 0.0368 & 0.0374 & 0.0331 & 0.0354 & 0.0410 & 0.0378 & 0.0498 & 0.0358 \\
\hline \multirow{3}{*}{ Japan } & Total & 0.0251 & 0.0221 & 0.0214 & 0.0266 & 0.0162 & 0.0237 & 0.0278 & 0.0213 & 0.0213 & 0.0218 \\
\hline & Non-Crisis & 0.0227 & 0.0196 & 0.0175 & 0.0232 & 0.0143 & 0.0207 & 0.0235 & 0.0188 & 0.0189 & 0.0259 \\
\hline & Crisis & 0.0326 & 0.0283 & 0.0303 & 0.0365 & 0.0192 & 0.0316 & 0.0364 & 0.0285 & 0.0254 & 0.0197 \\
\hline \multirow{3}{*}{ ASEAN } & Total & 0.0258 & 0.0195 & 0.0233 & 0.0198 & 0.0204 & 0.0205 & 0.0286 & 0.0372 & 0.0198 & 0.0222 \\
\hline & Non-Crisis & 0.0224 & 0.0172 & 0.0196 & 0.0167 & 0.0172 & 0.0169 & 0.0248 & 0.0348 & 0.0182 & 0.0187 \\
\hline & Crisis & 0.0336 & 0.0254 & 0.0319 & 0.0274 & 0.0280 & 0.0259 & 0.0394 & 0.0447 & 0.0258 & 0.0313 \\
\hline \multirow{4}{*}{ US } & Total & 0.0229 & 0.0137 & 0.0171 & 0.0237 & 0.0155 & 0.0188 & 0.0214 & 0.0202 & 0.0176 & 0.0162 \\
\hline & Non-Crisis & 0.0186 & 0.0121 & 0.0146 & 0.0179 & 0.0140 & 0.0158 & 0.0183 & 0.0172 & 0.0145 & 0.0140 \\
\hline & Crisis & 0.0356 & 0.0185 & 0.0248 & 0.0416 & 0.0192 & 0.0269 & 0.0312 & 0.0283 & 0.0274 & 0.0239 \\
\hline & CVaR & Materials & Goods & Services & Financials & Health & Industrial & Oil \& Gas & Technol. & Telecom & Utilities \\
\hline \multirow{3}{*}{ China } & Total & 0.0431 & 0.0363 & 0.0388 & 0.0400 & 0.0359 & 0.0382 & 0.0405 & 0.0417 & 0.0551 & 0.0358 \\
\hline & Non-Crisis & 0.0370 & 0.0308 & 0.0342 & 0.0345 & 0.0319 & 0.0340 & 0.0312 & 0.0386 & 0.0495 & 0.0304 \\
\hline & Crisis & 0.0575 & 0.0493 & 0.0496 & 0.0530 & 0.0453 & 0.0480 & 0.0621 & 0.0489 & 0.0682 & 0.0487 \\
\hline \multirow{3}{*}{ Japan } & Total & 0.0367 & 0.0325 & 0.0305 & 0.0391 & 0.0260 & 0.0347 & 0.0398 & 0.0316 & 0.0308 & 0.0341 \\
\hline & Non-Crisis & 0.0323 & 0.0286 & 0.0253 & 0.0326 & 0.0242 & 0.0297 & 0.0356 & 0.0271 & 0.0288 & 0.0353 \\
\hline & Crisis & 0.0472 & 0.0416 & 0.0426 & 0.0545 & 0.0303 & 0.0465 & 0.0498 & 0.0422 & 0.0355 & 0.0313 \\
\hline \multirow{3}{*}{ ASEAN } & Total & 0.0437 & 0.0295 & 0.0336 & 0.0294 & 0.0348 & 0.0318 & 0.0419 & 0.0573 & 0.0319 & 0.0367 \\
\hline & Non-Crisis & 0.0371 & 0.0251 & 0.0289 & 0.0240 & 0.0287 & 0.0274 & 0.0352 & 0.0514 & 0.0281 & 0.0303 \\
\hline & Crisis & 0.0591 & 0.0397 & 0.0446 & 0.0421 & 0.0491 & 0.0420 & 0.0575 & 0.0711 & 0.0408 & 0.0517 \\
\hline \multirow{3}{*}{ US } & Total & 0.0355 & 0.0204 & 0.0250 & 0.0391 & 0.0231 & 0.0282 & 0.0349 & 0.0292 & 0.0262 & 0.0236 \\
\hline & Non-Crisis & 0.0278 & 0.0173 & 0.0199 & 0.0257 & 0.0207 & 0.0233 & 0.0283 & 0.0240 & 0.0196 & 0.0183 \\
\hline & Crisis & 0.0535 & 0.0276 & 0.0369 & 0.0704 & 0.0287 & 0.0395 & 0.0502 & 0.0414 & 0.0415 & 0.0357 \\
\hline
\end{tabular}


Table A2. 99\% VaR and CVaR per industry: 2007-2016.

\begin{tabular}{|c|c|c|c|c|c|c|c|c|c|c|c|}
\hline & Hist. & Materials & Goods & Services & Financials & Health & Industrial & Oil \& Gas & Technol. & Telecom & Utilities \\
\hline \multirow{3}{*}{ China } & Total & 0.0492 & 0.0408 & 0.0434 & 0.0472 & 0.0410 & 0.0444 & 0.0489 & 0.0472 & 0.0640 & 0.0404 \\
\hline & Non-Crisis & 0.0414 & 0.0348 & 0.0381 & 0.0413 & 0.0356 & 0.0394 & 0.0382 & 0.0443 & 0.0572 & 0.0342 \\
\hline & Crisis & 0.0675 & 0.0549 & 0.0557 & 0.0611 & 0.0535 & 0.0561 & 0.0739 & 0.0539 & 0.0798 & 0.0546 \\
\hline \multirow{3}{*}{ Japan } & Total & 0.0415 & 0.0369 & 0.0348 & 0.0450 & 0.0301 & 0.0387 & 0.0466 & 0.0365 & 0.0358 & 0.0389 \\
\hline & Non-Crisis & 0.0357 & 0.0314 & 0.0280 & 0.0365 & 0.0277 & 0.0328 & 0.0405 & 0.0315 & 0.0324 & 0.0403 \\
\hline & Crisis & 0.0551 & 0.0496 & 0.0505 & 0.0647 & 0.0358 & 0.0526 & 0.0606 & 0.0483 & 0.0437 & 0.0356 \\
\hline \multirow{3}{*}{ ASEAN } & Total & 0.0520 & 0.0344 & 0.0391 & 0.0337 & 0.0341 & 0.0365 & 0.0451 & 0.0694 & 0.0360 & 0.0426 \\
\hline & Non-Crisis & 0.0415 & 0.0287 & 0.0330 & 0.0271 & 0.0272 & 0.0312 & 0.0402 & 0.0544 & 0.0317 & 0.0347 \\
\hline & Crisis & 0.0741 & 0.0476 & 0.0534 & 0.0490 & 0.0502 & 0.0486 & 0.0594 & 0.0872 & 0.0461 & 0.0609 \\
\hline \multirow{4}{*}{ US } & Total & 0.0413 & 0.0233 & 0.0281 & 0.0460 & 0.0264 & 0.0324 & 0.0410 & 0.0327 & 0.0299 & 0.0284 \\
\hline & Non-Crisis & 0.0319 & 0.0198 & 0.0222 & 0.0303 & 0.0238 & 0.0266 & 0.0326 & 0.0276 & 0.0226 & 0.0211 \\
\hline & Crisis & 0.0632 & 0.0315 & 0.0418 & 0.0826 & 0.0325 & 0.0457 & 0.0606 & 0.0446 & 0.0470 & 0.0456 \\
\hline & Para. VaR & Materials & Goods & Services & Financials & Health & Industrial & Oil \& Gas & Technol. & Telecom & Utilities \\
\hline \multirow{3}{*}{ China } & Total & 0.0498 & 0.0420 & 0.0470 & 0.0416 & 0.0410 & 0.0446 & 0.0420 & 0.0505 & 0.0560 & 0.0419 \\
\hline & Non-Crisis & 0.0423 & 0.0353 & 0.0411 & 0.0344 & 0.0361 & 0.0387 & 0.0329 & 0.0464 & 0.0489 & 0.0342 \\
\hline & Crisis & 0.0675 & 0.0576 & 0.0608 & 0.0582 & 0.0524 & 0.0584 & 0.0632 & 0.0600 & 0.0727 & 0.0601 \\
\hline \multirow{3}{*}{ Japan } & Total & 0.0415 & 0.0358 & 0.0332 & 0.0418 & 0.0297 & 0.0389 & 0.0444 & 0.0361 & 0.0340 & 0.0375 \\
\hline & Non-Crisis & 0.0362 & 0.0315 & 0.0273 & 0.0351 & 0.0274 & 0.0334 & 0.0384 & 0.0309 & 0.0313 & 0.0391 \\
\hline & Crisis & 0.0540 & 0.0457 & 0.0470 & 0.0574 & 0.0352 & 0.0519 & 0.0582 & 0.0482 & 0.0405 & 0.0339 \\
\hline \multirow{3}{*}{ ASEAN } & Total & 0.0461 & 0.0311 & 0.0351 & 0.0312 & 0.0301 & 0.0336 & 0.0439 & 0.0575 & 0.0333 & 0.0379 \\
\hline & Non-Crisis & 0.0395 & 0.0269 & 0.0294 & 0.0258 & 0.0251 & 0.0290 & 0.0366 & 0.0525 & 0.0291 & 0.0315 \\
\hline & Crisis & 0.0616 & 0.0409 & 0.0485 & 0.0437 & 0.0416 & 0.0443 & 0.0610 & 0.0691 & 0.0432 & 0.0530 \\
\hline \multirow{4}{*}{ US } & Total & 0.0404 & 0.0224 & 0.0273 & 0.0406 & 0.0250 & 0.0311 & 0.0388 & 0.0312 & 0.0280 & 0.0261 \\
\hline & Non-Crisis & 0.0308 & 0.0190 & 0.0221 & 0.0275 & 0.0224 & 0.0253 & 0.0312 & 0.0258 & 0.0214 & 0.0207 \\
\hline & Crisis & 0.0628 & 0.0303 & 0.0395 & 0.0713 & 0.0310 & 0.0445 & 0.0566 & 0.0439 & 0.0436 & 0.0386 \\
\hline & Mod. VaR & Materials & Goods & Services & Financials & Health & Industrial & Oil \& Gas & Technol. & Telecom & Utilities \\
\hline \multirow{3}{*}{ China } & Total & 0.0539 & 0.0475 & 0.0472 & 0.0552 & 0.0464 & 0.0491 & 0.0653 & 0.0508 & 0.0789 & 0.0476 \\
\hline & Non-Crisis & 0.0475 & 0.0420 & 0.0418 & 0.0510 & 0.0415 & 0.0451 & 0.0598 & 0.0469 & 0.0793 & 0.0452 \\
\hline & Crisis & 0.0645 & 0.0561 & 0.0559 & 0.0640 & 0.0538 & 0.0567 & 0.0764 & 0.0579 & 0.0827 & 0.0552 \\
\hline
\end{tabular}


Table A2. Cont.

\begin{tabular}{|c|c|c|c|c|c|c|c|c|c|c|c|}
\hline & Mod. VaR & Materials & Goods & Services & Financials & Health & Industrial & Oil \& Gas & Technol. & Telecom & Utilities \\
\hline \multirow{3}{*}{ Japan } & Total & 0.0680 & 0.0551 & 0.0605 & 0.0653 & 0.0494 & 0.0607 & 0.0604 & 0.0523 & 0.0525 & 0.0614 \\
\hline & Non-Crisis & 0.0508 & 0.0430 & 0.0466 & 0.0492 & 0.0418 & 0.0429 & 0.0492 & 0.0367 & 0.0517 & 0.0634 \\
\hline & Crisis & 0.0837 & 0.0669 & 0.0700 & 0.0802 & 0.0574 & 0.0755 & 0.0704 & 0.0656 & 0.0542 & 0.0531 \\
\hline \multirow{3}{*}{ ASEAN } & Total & 0.0808 & 0.0529 & 0.0524 & 0.0463 & 0.0463 & 0.0544 & 0.0774 & 0.1007 & 0.0561 & 0.0730 \\
\hline & Non-Crisis & 0.0622 & 0.0425 & 0.0397 & 0.0326 & 0.0384 & 0.0361 & 0.0623 & 0.0836 & 0.0457 & 0.0415 \\
\hline & Crisis & 0.0889 & 0.0537 & 0.0661 & 0.0541 & 0.0526 & 0.0629 & 0.0873 & 0.1100 & 0.0596 & 0.0934 \\
\hline \multirow{4}{*}{ US } & Total & 0.0645 & 0.0425 & 0.0491 & 0.0860 & 0.0467 & 0.0452 & 0.0813 & 0.0517 & 0.0664 & 0.0639 \\
\hline & Non-Crisis & 0.0385 & 0.0220 & 0.0260 & 0.0407 & 0.0255 & 0.0317 & 0.0372 & 0.0302 & 0.0243 & 0.0233 \\
\hline & Crisis & 0.0785 & 0.0557 & 0.0623 & 0.1042 & 0.0651 & 0.0560 & 0.0992 & 0.0664 & 0.0810 & 0.0807 \\
\hline & CVaR & Materials & Goods & Services & Financials & Health & Industrial & Oil \& Gas & Technol. & Telecom & Utilities \\
\hline \multirow{3}{*}{ China } & Total & 0.0580 & 0.0481 & 0.0499 & 0.0539 & 0.0468 & 0.0505 & 0.0562 & 0.0527 & 0.0752 & 0.0483 \\
\hline & Non-Crisis & 0.0510 & 0.0413 & 0.0441 & 0.0472 & 0.0406 & 0.0454 & 0.0463 & 0.0484 & 0.0700 & 0.0420 \\
\hline & Crisis & 0.0744 & 0.0641 & 0.0634 & 0.0696 & 0.0612 & 0.0623 & 0.0795 & 0.0628 & 0.0873 & 0.0630 \\
\hline \multirow{3}{*}{ Japan } & Total & 0.0541 & 0.0472 & 0.0441 & 0.0564 & 0.0382 & 0.0497 & 0.0567 & 0.0444 & 0.0472 & 0.0514 \\
\hline & Non-Crisis & 0.0467 & 0.0415 & 0.0354 & 0.0471 & 0.0356 & 0.0424 & 0.0506 & 0.0381 & 0.0453 & 0.0529 \\
\hline & Crisis & 0.0713 & 0.0606 & 0.0644 & 0.0783 & 0.0444 & 0.0667 & 0.0709 & 0.0593 & 0.0516 & 0.0477 \\
\hline \multirow{3}{*}{ ASEAN } & Total & 0.0668 & 0.0420 & 0.0480 & 0.0416 & 0.0436 & 0.0449 & 0.0550 & 0.0882 & 0.0470 & 0.0528 \\
\hline & Non-Crisis & 0.0559 & 0.0359 & 0.0410 & 0.0337 & 0.0353 & 0.0379 & 0.0534 & 0.0771 & 0.0415 & 0.0430 \\
\hline & Crisis & 0.0864 & 0.0564 & 0.0643 & 0.0601 & 0.0628 & 0.0611 & 0.0799 & 0.1061 & 0.0596 & 0.0757 \\
\hline \multirow{3}{*}{ US } & Total & 0.0481 & 0.0293 & 0.0351 & 0.0532 & 0.0331 & 0.0385 & 0.0482 & 0.0416 & 0.0377 & 0.0337 \\
\hline & Non-Crisis & 0.0366 & 0.0232 & 0.0261 & 0.0350 & 0.0276 & 0.0304 & 0.0373 & 0.0324 & 0.0264 & 0.0242 \\
\hline & Crisis & 0.0748 & 0.0436 & 0.0559 & 0.0958 & 0.0459 & 0.0574 & 0.0734 & 0.0630 & 0.0642 & 0.0558 \\
\hline
\end{tabular}


Table A3. 95\% VaR and CVaR rankings per industry: 2007-2016.

\begin{tabular}{|c|c|c|c|c|c|c|c|c|c|c|c|}
\hline & Hist. & Materials & Goods & Services & Financials & Health & Industrial & Oil \& Gas & Technol. & Telecom & Utilities \\
\hline \multirow{3}{*}{ China } & Total & 8 & 3 & 7 & 5 & 2 & 6 & 1 & 9 & 10 & 4 \\
\hline & Non-Crisis & 8 & 3 & 7 & 4 & 5 & 6 & 1 & 9 & 10 & 2 \\
\hline & Crisis & 9 & 4 & 6 & 2 & 1 & 3 & 5 & 8 & 10 & 7 \\
\hline \multirow{3}{*}{ Japan } & Total & 9 & 4 & 3 & 8 & 1 & 7 & 10 & 5 & 2 & 6 \\
\hline & Non-Crisis & 8 & 5 & 2 & 7 & 1 & 6 & 10 & 4 & 3 & 9 \\
\hline & Crisis & 8 & 4 & 5 & 9 & 1 & 7 & 10 & 6 & 3 & 2 \\
\hline \multirow{3}{*}{ ASEAN } & Total & 9 & 1 & 6 & 2 & 5 & 4 & 8 & 10 & 3 & 7 \\
\hline & Non-Crisis & 9 & 2 & 6 & 1 & 4 & 3 & 8 & 10 & 5 & 7 \\
\hline & Crisis & 8 & 1 & 6 & 3 & 4 & 5 & 9 & 10 & 2 & 7 \\
\hline \multirow{4}{*}{ US } & Total & 10 & 1 & 4 & 9 & 2 & 6 & 8 & 7 & 5 & 3 \\
\hline & Non-Crisis & 10 & 1 & 4 & 8 & 5 & 6 & 9 & 7 & 3 & 2 \\
\hline & Crisis & 9 & 1 & 4 & 10 & 2 & 6 & 8 & 7 & 5 & 3 \\
\hline & Para. VaR & Materials & Goods & Services & Financials & Health & Industrial & Oil \& Gas & Technol. & Telecom & Utilities \\
\hline \multirow{3}{*}{ China } & Total & 8 & 4 & 7 & 2 & 1 & 6 & 5 & 9 & 10 & 3 \\
\hline & Non-Crisis & 8 & 4 & 7 & 3 & 5 & 6 & 1 & 9 & 10 & 2 \\
\hline & Crisis & 9 & 2 & 7 & 3 & 1 & 4 & 8 & 5 & 10 & 6 \\
\hline \multirow{3}{*}{ Japan } & Total & 8 & 4 & 2 & 9 & 1 & 7 & 10 & 5 & 3 & 6 \\
\hline & Non-Crisis & 8 & 5 & 1 & 7 & 2 & 6 & 9 & 3 & 4 & 10 \\
\hline & Crisis & 8 & 4 & 5 & 9 & 2 & 7 & 10 & 6 & 3 & 1 \\
\hline \multirow{3}{*}{ ASEAN } & Total & 9 & 1 & 5 & 2 & 6 & 4 & 8 & 10 & 3 & 7 \\
\hline & Non-Crisis & 9 & 2 & 5 & 1 & 6 & 3 & 8 & 10 & 4 & 7 \\
\hline & Crisis & 8 & 1 & 5 & 3 & 6 & 4 & 9 & 10 & 2 & 7 \\
\hline \multirow{4}{*}{ US } & Total & 9 & 1 & 4 & 10 & 2 & 6 & 8 & 7 & 5 & 3 \\
\hline & Non-Crisis & 9 & 1 & 4 & 8 & 5 & 6 & 10 & 7 & 3 & 2 \\
\hline & Crisis & 9 & 1 & 4 & 10 & 2 & 7 & 8 & 6 & 5 & 3 \\
\hline & Mod. VaR & Materials & Goods & Services & Financials & Health & Industrial & Oil \& Gas & Technol. & Telecom & Utilities \\
\hline \multirow{3}{*}{ China } & Total & 8 & 2 & 7 & 4 & 3 & 5 & 6 & 9 & 10 & 1 \\
\hline & Non-Crisis & 8 & 2 & 7 & 4 & 5 & 6 & 3 & 9 & 10 & 1 \\
\hline & Crisis & 9 & 2 & 5 & 6 & 1 & 3 & 8 & 7 & 10 & 4 \\
\hline
\end{tabular}


Table A3. Cont.

\begin{tabular}{|c|c|c|c|c|c|c|c|c|c|c|c|}
\hline & Mod. VaR & Materials & Goods & Services & Financials & Health & Industrial & Oil \& Gas & Technol. & Telecom & Utilities \\
\hline \multirow{3}{*}{ Japan } & Total & 8 & 6 & 4 & 9 & 1 & 7 & 10 & 2 & 3 & 5 \\
\hline & Non-Crisis & 7 & 5 & 2 & 8 & 1 & 6 & 9 & 3 & 4 & 10 \\
\hline & Crisis & 8 & 4 & 6 & 10 & 1 & 7 & 9 & 5 & 3 & 2 \\
\hline \multirow{3}{*}{ ASEAN } & Total & 8 & 1 & 7 & 2 & 4 & 5 & 9 & 10 & 3 & 6 \\
\hline & Non-Crisis & 8 & 3 & 7 & 1 & 4 & 2 & 9 & 10 & 5 & 6 \\
\hline & Crisis & 8 & 1 & 7 & 4 & 5 & 3 & 9 & 10 & 2 & 6 \\
\hline \multirow{4}{*}{ US } & Total & 9 & 1 & 4 & 10 & 2 & 6 & 8 & 7 & 5 & 3 \\
\hline & Non-Crisis & 10 & 1 & 5 & 8 & 3 & 6 & 9 & 7 & 4 & 2 \\
\hline & Crisis & 9 & 1 & 4 & 10 & 2 & 5 & 8 & 7 & 6 & 3 \\
\hline & CVaR & Materials & Goods & Services & Financials & Health & Industrial & Oil \& Gas & Technol. & Telecom & Utilities \\
\hline \multirow{3}{*}{ China } & Total & 9 & 3 & 5 & 6 & 2 & 4 & 7 & 8 & 10 & 1 \\
\hline & Non-Crisis & 8 & 2 & 6 & 7 & 4 & 5 & 3 & 9 & 10 & 1 \\
\hline & Crisis & 8 & 5 & 6 & 7 & 1 & 2 & 9 & 4 & 10 & 3 \\
\hline \multirow{3}{*}{ Japan } & Total & 8 & 5 & 2 & 9 & 1 & 7 & 10 & 4 & 3 & 6 \\
\hline & Non-Crisis & 7 & 4 & 2 & 8 & 1 & 6 & 10 & 3 & 5 & 9 \\
\hline & Crisis & 8 & 4 & 6 & 10 & 1 & 7 & 9 & 5 & 3 & 2 \\
\hline \multirow{3}{*}{ ASEAN } & Total & 9 & 2 & 5 & 1 & 6 & 3 & 8 & 10 & 4 & 7 \\
\hline & Non-Crisis & 9 & 2 & 6 & 1 & 5 & 3 & 8 & 10 & 4 & 7 \\
\hline & Crisis & 9 & 1 & 5 & 4 & 6 & 3 & 8 & 10 & 2 & 7 \\
\hline \multirow{3}{*}{ US } & Total & 9 & 1 & 4 & 10 & 2 & 6 & 8 & 7 & 5 & 3 \\
\hline & Non-Crisis & 9 & 1 & 4 & 8 & 5 & 6 & 10 & 7 & 3 & 2 \\
\hline & Crisis & 9 & 1 & 4 & 10 & 2 & 5 & 8 & 6 & 7 & 3 \\
\hline
\end{tabular}


Table A4. 99\% VaR and CVaR rankings per industry: 2007-2016.

\begin{tabular}{|c|c|c|c|c|c|c|c|c|c|c|c|}
\hline & Hist. & Materials & Goods & Services & Financials & Health & Industrial & Oil \& Gas & Technol. & Telecom & Utilities \\
\hline \multirow{3}{*}{ China } & Total & 9 & 2 & 4 & 7 & 3 & 5 & 8 & 6 & 10 & 1 \\
\hline & Non-Crisis & 8 & 2 & 4 & 7 & 3 & 6 & 5 & 9 & 10 & 1 \\
\hline & Crisis & 8 & 4 & 5 & 7 & 1 & 6 & 9 & 2 & 10 & 3 \\
\hline \multirow{3}{*}{ Japan } & Total & 8 & 5 & 2 & 9 & 1 & 6 & 10 & 4 & 3 & 7 \\
\hline & Non-Crisis & 7 & 3 & 2 & 8 & 1 & 6 & 10 & 4 & 5 & 9 \\
\hline & Crisis & 8 & 5 & 6 & 10 & 2 & 7 & 9 & 4 & 3 & 1 \\
\hline \multirow{3}{*}{ ASEAN } & Total & 9 & 3 & 6 & 1 & 2 & 5 & 8 & 10 & 4 & 7 \\
\hline & Non-Crisis & 9 & 3 & 6 & 1 & 2 & 4 & 8 & 10 & 5 & 7 \\
\hline & Crisis & 9 & 2 & 6 & 4 & 5 & 3 & 8 & 10 & 1 & 7 \\
\hline \multirow{4}{*}{ US } & Total & 9 & 1 & 3 & 10 & 2 & 6 & 8 & 7 & 5 & 4 \\
\hline & Non-Crisis & 9 & 1 & 3 & 8 & 5 & 6 & 10 & 7 & 4 & 2 \\
\hline & Crisis & 9 & 1 & 3 & 10 & 2 & 6 & 8 & 4 & 7 & 5 \\
\hline & Para. VaR & Materials & Goods & Services & Financials & Health & Industrial & Oil \& Gas & Technol. & Telecom & Utilities \\
\hline \multirow{3}{*}{ China } & Total & 8 & 4 & 7 & 2 & 1 & 6 & 5 & 9 & 10 & 3 \\
\hline & Non-Crisis & 8 & 4 & 7 & 3 & 5 & 6 & 1 & 9 & 10 & 2 \\
\hline & Crisis & 9 & 2 & 7 & 3 & 1 & 4 & 8 & 5 & 10 & 6 \\
\hline \multirow{3}{*}{ Japan } & Total & 8 & 4 & 2 & 9 & 1 & 7 & 10 & 5 & 3 & 6 \\
\hline & Non-Crisis & 8 & 5 & 1 & 7 & 2 & 6 & 9 & 3 & 4 & 10 \\
\hline & Crisis & 8 & 4 & 5 & 9 & 2 & 7 & 10 & 6 & 3 & 1 \\
\hline \multirow{3}{*}{ ASEAN } & Total & 9 & 2 & 6 & 3 & 1 & 5 & 8 & 10 & 4 & 7 \\
\hline & Non-Crisis & 9 & 3 & 6 & 2 & 1 & 4 & 8 & 10 & 5 & 7 \\
\hline & Crisis & 9 & 1 & 6 & 4 & 2 & 5 & 8 & 10 & 3 & 7 \\
\hline \multirow{4}{*}{ US } & Total & 9 & 1 & 4 & 10 & 2 & 6 & 8 & 7 & 5 & 3 \\
\hline & Non-Crisis & 9 & 1 & 4 & 8 & 5 & 6 & 10 & 7 & 3 & 2 \\
\hline & Crisis & 9 & 1 & 4 & 10 & 2 & 7 & 8 & 6 & 5 & 3 \\
\hline & Mod. VaR & Materials & Goods & Services & Financials & Health & Industrial & Oil \& Gas & Technol. & Telecom & Utilities \\
\hline \multirow{3}{*}{ China } & Total & 7 & 3 & 2 & 8 & 1 & 5 & 9 & 6 & 10 & 4 \\
\hline & Non-Crisis & 7 & 3 & 2 & 8 & 1 & 4 & 9 & 6 & 10 & 5 \\
\hline & Crisis & 8 & 4 & 3 & 7 & 1 & 5 & 9 & 6 & 10 & 2 \\
\hline
\end{tabular}


Table A4. Cont.

\begin{tabular}{|c|c|c|c|c|c|c|c|c|c|c|c|}
\hline & Mod. VaR & Materials & Goods & Services & Financials & Health & Industrial & Oil \& Gas & Technol. & Telecom & Utilities \\
\hline \multirow{3}{*}{ Japan } & Total & 10 & 4 & 6 & 9 & 1 & 7 & 5 & 2 & 3 & 8 \\
\hline & Non-Crisis & 8 & 4 & 5 & 6 & 2 & 3 & 7 & 1 & 9 & 10 \\
\hline & Crisis & 10 & 5 & 6 & 9 & 3 & 8 & 7 & 4 & 2 & 1 \\
\hline \multirow{3}{*}{ ASEAN } & Total & 9 & 4 & 3 & 2 & 1 & 5 & 8 & 10 & 6 & 7 \\
\hline & Non-Crisis & 8 & 6 & 4 & 1 & 3 & 2 & 9 & 10 & 7 & 5 \\
\hline & Crisis & 8 & 2 & 6 & 3 & 1 & 5 & 7 & 10 & 4 & 9 \\
\hline \multirow{4}{*}{ US } & Total & 7 & 1 & 4 & 10 & 3 & 2 & 9 & 5 & 8 & 6 \\
\hline & Non-Crisis & 9 & 1 & 5 & 10 & 4 & 7 & 8 & 6 & 3 & 2 \\
\hline & Crisis & 6 & 1 & 3 & 10 & 4 & 2 & 9 & 5 & 8 & 7 \\
\hline & CVaR & Materials & Goods & Services & Financials & Health & Industrial & Oil \& Gas & Technol. & Telecom & Utilities \\
\hline \multirow{3}{*}{ China } & Total & 9 & 2 & 4 & 7 & 1 & 5 & 8 & 6 & 10 & 3 \\
\hline & Non-Crisis & 9 & 2 & 4 & 7 & 1 & 5 & 6 & 8 & 10 & 3 \\
\hline & Crisis & 8 & 6 & 5 & 7 & 1 & 2 & 9 & 3 & 10 & 4 \\
\hline \multirow{3}{*}{ Japan } & Total & 8 & 5 & 2 & 9 & 1 & 6 & 10 & 3 & 4 & 7 \\
\hline & Non-Crisis & 7 & 4 & 1 & 8 & 2 & 5 & 9 & 3 & 6 & 10 \\
\hline & Crisis & 9 & 5 & 6 & 10 & 1 & 7 & 8 & 4 & 3 & 2 \\
\hline \multirow{3}{*}{ ASEAN } & Total & 9 & 2 & 6 & 1 & 3 & 4 & 8 & 10 & 5 & 7 \\
\hline & Non-Crisis & 9 & 3 & 5 & 1 & 2 & 4 & 8 & 10 & 6 & 7 \\
\hline & Crisis & 9 & 1 & 6 & 3 & 5 & 4 & 8 & 10 & 2 & 7 \\
\hline \multirow{3}{*}{ US } & Total & 8 & 1 & 4 & 10 & 2 & 6 & 9 & 7 & 5 & 3 \\
\hline & Non Crisis & 9 & 1 & 3 & 8 & 5 & 6 & 10 & 7 & 4 & 2 \\
\hline & Crisis & 9 & 1 & 4 & 10 & 2 & 5 & 8 & 6 & 7 & 3 \\
\hline
\end{tabular}




\section{References}

Äijö, Janne, and Vitaly Orlov. 2015. Benefits of wavelet-based carry trade. Research in International Business and Finance 34: 17-32.

Allen, David E., Paul Gerrans, Robert J. Powell, and Abhay K. Singh. 2009. Quantile regression: Its application in investment analysis. JASSA 4: 7-12.

Allen, David E., Raymond R. Boffey, Akhmad R. Kramadibrata, Robert J. Powell, and Abhay K. Singh. 2012. Thumbs up to parametric measures of relative VaR and CVaR in Indonesian sectors. International Journal of Business Studies 20: 27-42.

Allen, David E., Robert J. Powell, and Abhay K. Singh. 2016. Take it to the limit: Innovative CVaR applications to extreme credit risk measurement. European Journal of Operational Research 249: 465-75. [CrossRef]

Amato, Jeffery D., and Craig H. Furfine. 2004. Are credit ratings procyclical? Journal of Banking E Finance 28: 2641-77.

Batten, Jonathan A., Peter Morgan, and Peter G. Szilagyi. 2015. Time varying Asian stock market integration. Singapore Economic Review 60: 1-24. [CrossRef]

Baur, Dirk G. 2012. Financial contagion and the real economy. Journal of Banking and Finance 36: 2680-98. [CrossRef]

Brown, Kim, Jonathan A. Batten, Michael T. Skully, and Yen N. Nguyen. 2014. Comparative financial development in Asia-Pacific since the Asia crisis. In Handbook of Asian Finance: Financial Markets and Sovereign Wealth Funds, 1st ed. Edited by David Lee, Kuo Chuen and Greg. N. Gregoriou. San Diego: Academic Press, vol. 1, pp. 237-50.

Cantor, Richard, and Christopher Mann. 2003. Measuring the performance of corporate bond ratings. Moodys Special Comment, April.

Chiang, Thomas C., Bang N. Jeon, and Huimin Li. 2007. Dynamic correlation analysis of financial contagion: Evidence from Asian markets. Journal of International Money and Finance 26: 1206-28. [CrossRef]

Choudhry, Moorad. 2013. An Introduction to Value at Risk, 5th ed. Chichester: John Wiley and Sons.

Chuang, I.-Yuan, Jin-Ray Lu, and Keshin Tswei. 2007. Interdependence of international equity variances: Evidence from East Asian Markets. Emerging Markets Review 8: 311-27. [CrossRef]

Click, Reid W., and Michael Plummer. 2005. Stock market integration in ASEAN after the Asian financial crisis. Journal of Asian Economics 16: 5-28. [CrossRef]

Cornish, Edmund A., and Ronald A. Fisher. 1938. Moments and Cumulants in the Specification of Distributions. Review of the International Statistical Institute. International Statistical Institute 5: 307-20. [CrossRef]

Dedania, Haresh V., Vipul R. Shah, and Rajesh C. Sanghvi. 2015. Portfolio Management: Stock Ranking by Multiple Attribute Decision Making Methods. Technology and Investment 6: 141-50. [CrossRef]

Del Brio, Esther B., Andrés Mora-Valencia, and Javier Perote. 2014. VaR performance during the subprime and sovereign debt crises: An application to emerging markets. Emerging Markets Review 20: 23-41. [CrossRef]

Furió, Dolores, and Francisco. J. Climent. 2013. Extreme value theory versus traditional GARCH approaches applied to financial data: a comparative evaluation. Quantitative Finance 13: 45-63. [CrossRef]

Hakamada, Takesi, Akihiko Takahashi, and Kyo Yamamoto. 2007. Selection and performance analysis of Asia-Pacific hedge funds. The Journal of Alternative Investments 10: 7-29. [CrossRef]

International Monetary Fund. 2017. World Economic Outlook April. Available online: https://www.imf.org/ external/pubs/ft/weo/2017/01/weodata/index.aspx (accessed on 17 August 2018).

Kenourgios, Dimitris, and Dimitrios Dimitriou. 2015. Contagion of the global financial crisis and the real economy: A regional analysis. Economic Modelling 44: 283-93. [CrossRef]

Koenker, Roger, and Gilbert Bassett. 1978. Regression Quantiles. Econometrica 46: 33-50. [CrossRef]

Li, Jing, and Mingxin Xu. 2013. Optimal Dynamic Portfolio with Mean-CVaR Criterion. Risks 1: 119-47. [CrossRef]

Lim, Kian G. 2012. Global financial risks, CVaR and contagion management. Journal of Business and Policy Research 7: 115-30.

Markowitz, Harry. 1952. Portfolio Selection. The Journal of Finance 7: 77-91.

Narayan, Paresh K., Seema Narayan, Dinh H. B. Phan, Kannan S. Thuraisamy, and Vuong T. Tran. 2017. Credit quality implied momentum profits for Islamic stocks. Pacific-Basin Finance Journal 42: 11-23. [CrossRef]

Pinelis, Iosif. 2014. An Optimal Three-Way Stable and Monotonic Spectrum of Bounds on Quantiles: A Spectrum of Coherent Measures of Financial Risk and Economic Inequality. Risks 2: 349-92. [CrossRef] 
Rejeb, Aymen B., and Mongi Arfaoui. 2016. Financial market interdependencies: A quantile regression analysis of volatility spillover. Research in International Business and Finance 36: 140-57. [CrossRef]

Thomasz, Esteban Otto, and Aurelio Fernández Bariviera. 2013. Risk behaviour of stock markets before and after the subprime crisis. In Modeling and Simulation in Engineering, Economics, and Management, Paper Presented at the Modeling and Simulation in Engineering, Economics, and Management: International Conference (MS 2013), Castellón de la Plana, Spain, June 6-7. Edited by María Ángeles Fernández-Izquierdo, María Jesús Muñoz-Torres and Raúl León. Berlin and Heidelberg: Springer, pp. 83-90. [CrossRef]

Uryasev, Stanislav, and R. Tyrell Rockafellar. 2000. Optimization of conditional value-at-Risk. Journal of Risk 2: 21-41.

Yamai, Yasuhiro, and Toshinao Yoshiba. 2005. Value-at-risk versus expected shortfall: A practical perspective. Journal of Banking \& Finance 29: 997-1015.

Yang, Jian, James W. Kolari, and Insik Min. 2010. Stock market integration and financial crises: The case of Asia. Applied Financial Economics 13: 477-86. [CrossRef]

Yu, Jinping, Xiaofeng Yang, and Shenghong Li. 2009. Portfolio optimization with CVaR under VG process. Research in International Business and Finance 23: 107-16. [CrossRef]

(C) 2018 by the authors. Licensee MDPI, Basel, Switzerland. This article is an open access article distributed under the terms and conditions of the Creative Commons Attribution (CC BY) license (http:/ / creativecommons.org/licenses/by/4.0/). 